ORNL/TM-12670

Dist. Category UC-420

Fusion Energy Division

\title{
EVALUATION OF TORSATRONS AS REACTORS
}

\author{
J. F. Lyon* \\ K. Gulec ${ }^{\dagger}$ \\ R. L. Miller $\ddagger$ \\ L. El-Guebaly ${ }^{* *}$
}

*Oak Ridge National Laboratory.

tUniversity of Tennessee, Knoxville.

¥Los Alamos National Laboratory.

${ }^{* *}$ University of Wisconsin.

Date Published: March 1994

\author{
Prepared for the \\ DOE Office of Fusion Energy \\ Budget Activity No. AT 1503000 \\ Prepared by \\ OAK RIDGE NATIONAL LABORATORY \\ Oak Ridge, Tennessee 37831-6285 \\ managed by \\ MARTIN MARIETTA ENERGY SYSTEMS, INC. \\ for the \\ U.S. DEPARTMENT OF ENERGY \\ under contract DE-AC05-84OR21400
}




\section{CONTENTS}

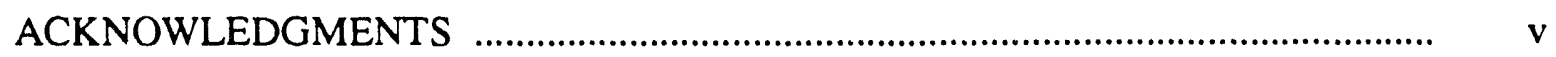

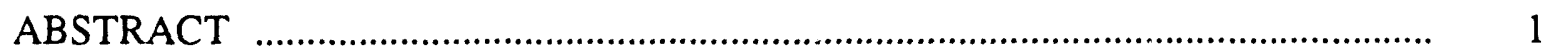

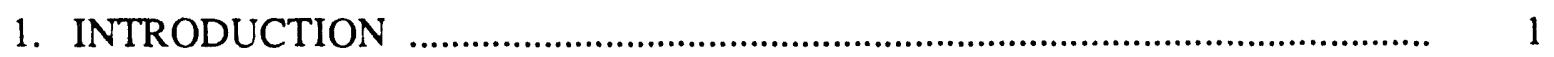

2. REACTOR ASSESSMENT APPROACH AND ASSUMPTIONS ……………... 3

2.1 REFERENCE STELLARATOR CONFIGURATION ................................. 3

2.2 REACTOR COMPONENT ASSUMPTIONS ……………………………... 3

2.3 TRANSPORT ASSUMPTIONS ……………………..............................

2.4 TRANSPORT MODEL …………………………............................ 7

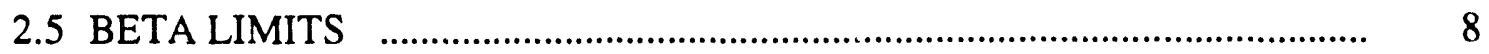

2.6 REACTOR OPTIMIZATION ………………………............................ 8

3. COMPARISONS WITH ARIES TOKAMAK REACTORS …............................ 10

3.1 COMPARISON OF PLASMA PARAMETERS …….................................... 10

3.2 COMPARISON OF DEVICE PARAMETERS …………............................. 11

4. SENSITIVITY OF THE REFERENCE CT6 CASE

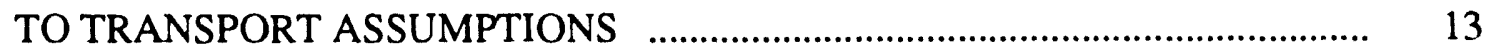

4.1 RADIAL PROFILES FOR THE REFERENCE CT6 CASE ……………....... 13

4.2 SENSITIVITY TO CONFINEMENT IMPROVEMENT .............................. 15

5. EFFECTS OF OTHER ASSUMPTIONS ………….......................................... 19

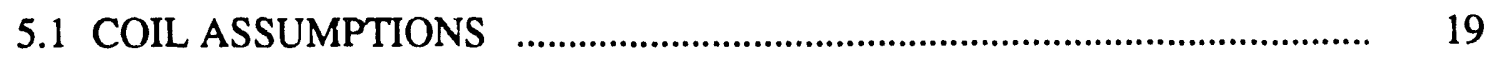

5.2 OTHER PARAMETER ASSUMPTIONS ……………………………........ 21

5.3 LFFECT OF ALPHA-PARTICLE LOSSES …………............................... 22

5.4 OTHER COIL CONFIGURATIONS …………………............................... 23

5.5 SCALING WITH ELECTRIC POWER OUTPUT ………………………..... 25

5.6 MORE CONSERVATIVE ASSUMPTIONS FOR THE BLANKET

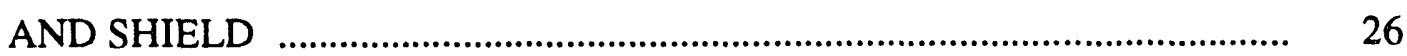

5.7 EFFECT OF MODULARIZATION ......................................................... 27

6. CONCLUSIONS AND DISCUSSION ....................................................... 28

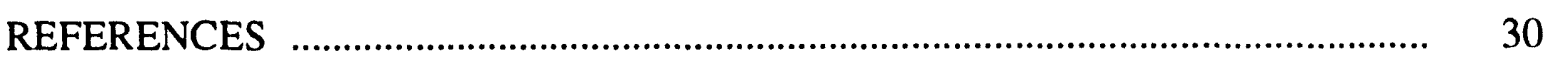




\section{ACKNOWLEDGMENTS}

The authors acknowledge useful discussions with the other members of the U.S. Stellarator Reactor Study Group (D. Anderson, L. Bromberg, F. Najmabadi, J. Rome, S. Sharafat, I. Sviatoslavsky, and C. Wong) and with B. Carreras, R. Fowler, P. Garabedian, J. Hanson, M. Peng. J. Sheffield, and N. Uckan. This research, at the Oak Ridge National Laboratory, was sponsored by the Office of Fusion Energy, U.S. Department of Energy, under contract DE-AC05-84OR21400 with Martin Marietta Energy Systems, Inc. 


\title{
EVALUATION OF TORSATRONS AS REACTORS
}

\author{
J. F. Lyon \\ R. L. Miller \\ K. Gulec \\ L. El-Guebaly
}

\begin{abstract}
Stellarators have significant operational advantages over tokamaks as ignited steadystate reactors. This scoping study, which uses an integrated cost minimization code that incorporates costing and reactor component models self-consistently with a 1-D energy transport calculation, shows that a torsatron reactor could also be economically competitive with a tokamak reactor. The projected cost of electricity (COE) estimated using the Advanced Reactor Innovation and Evaluation Studies (ARIES) costing algorithms is $65.6 \mathrm{mill} / \mathrm{kW}(\mathrm{e}) \mathrm{h}$ in constant 1992 dollars for a reference 1-GW(e) Compact Torsatron reactor case. The COE is relatively insensitive ( $<10 \%$ variation) over a wide range of assumptions, including variations in the maximum field allowed on the coils, the coil elongation, the shape of the density profile, the beta limit, the confinement multiplier, and the presence of a large loss region for alpha particles. The largest variations in the COE occur for variations in the electrical power output demanded and the plasma-coil separation ratio.
\end{abstract}

\section{INTRODUCTION}

Stellarators $[1,2]$ would have significant operational advantages as ig.ited steady-state reactors because they do not require a net plasma current (and the continuous power recirculated to the plasma to drive it). The magnetic field is created by currents flowing solely in external coils, resulting in inherently steady-state, disruption-free magnetic configurations with relaxed constraints on the plasma parameters and profiles and a wide range of magnetic configurations available for optimization and control. The absence of both dangerous disruptions and continuous current drive power recirculated to the plasma eases the design of the first wall, blanket, and shield. The larger aspect ratio may allow access from both the inboard and outboard sides for easier maintenance. The type of stellarator (a torsatron) used as an example in this paper can also have helical divertors outside the windings to reduce the power density on the divertor plates and, at the expense of a reduction in alpha-particle heating [3], a near-perpendicular loss region to prevent helium ash accumulation.

Although stellarators have the potential for leading to a better reactor, they lag behind tokamaks in their development because of the greater resources that have been devoted to tokamaks and the wider range of possible stellarator configurations. Stellarator reactor studies are also not as well-developed as tokamak reactor studies. The United States is starting a multiyear multi-institutional stellarator reactor study to "identify and assess the feasibility of critical issues and their consequences for development of the stellarator concept as a steadystate fusion reactor." The activities during the first year are focusing on physics optimization and selection of one or more stellarator coil configurations for more detailed engineering design evaluation. The physics team is focusing on development of transport models, overall 
system studies, torsatron modularization, modular stellarators with lower aspect ratio, and the divertor geometry. The engineering team is studying design issues relating to minimizing the inboard thickness of the blanket and shields, the feasibility of the superconducting magnets, the divertor geometry, and maintenance schemes. This paper summarizes the first phase of the work on systems studies, which will be updated as more detailed physics and engineering input is incorporated into the study. 


\section{REACTOR ASSESSMENT APPROACH AND ASSUMPTIONS}

The recent extensive Advanced Reactor Innovation and Evaluation Studies (ARIES) $[4,5]$ have explored improving the attractiveness of tokamak reactors. Our study applies the ARIES costing and component assumptions to optimization of stellarator reactors, which allows more accurate comparison of different stellarator and tokamak reactor configurations. The models for the detailed component geometry and reactor performance constraints are specialized in this paper for a particular torsatron reactor because of specific differences between types of stellarators and between stellarators and tokamaks.

\subsection{REFERENCE STELLARATOR CONFIGURATION}

The reference stellarator configuration chosen for these studies is a Compact Torsatron [6] with six toroidal field periods (CT6). It is not an "optimum" stellarator configuration, only one of a family of torsatrons obtained by maximizing the average radius of the last closed magnetic surface subject to constraints that maximized the beta limit. A torsatron is a stellarator with two continuous helical windings having currents in the same direction and no separate toroidal field (TF) coils. The helical windings produce both the toroidal and main poloidal field components, although separate vertical field (VF) coils may be used for shaping and positioning the plasma. The helical winding geometry and the last closed flux surface for the CT6 configuration are shown in fig. 1. The two helical windings are characterized by a coil aspect ratio $A_{\mathrm{c}} \equiv R_{0} / a_{\mathrm{c}}=2.5$, where $R_{0}$ and $a_{\mathrm{c}}$ are the major radius and minor radius of the helical winding. The relatively open coil geometry allows access between the helical windings for blanket removal and maintenance without disassembly of the reactor core. The vacuum magnetic surfaces were calculated using the optimized helical winding trajectory and VF coil locations. The last closed magnetic surface is characterized by an average plasma aspect ratio $A_{\mathrm{p}} \equiv R_{0} / a_{\mathrm{p}}=3.87$ and average ellipticity $\kappa=2.1$. Here $a_{\mathrm{p}}$ is the average radius of the noncircular (and nonaxisymmetric) last closed flux surface. As can be seen from fig. 1, $a_{\mathrm{p}}$ is relatively large compared to $a_{\mathrm{c}}$ because the plasma bulges out between the helical windings. Figure 2 shows a vertical cut through the plasma and the helical windings at the beginning of a $60^{\circ}$ toroidal field period. The thermal particles and alpha particles exit from the plasma in a thin helical strip between the helical windings. Although helical windings are used in this paper for simplicity, these coils can be modularized to have one (or two) coils per toroidal field period (e.g., the "symmotron" [7]) or five to ten coils per field period (as in a modular stellarator [8]).

\subsection{REACTOR COMPONENT ASSUMPTIONS}

The study assumes the same lcvel of technology development ("achievable in 20 years") as in the ARIES-IV study [9]. The compositions, average mass densities, and unit costs for the first-wall/blanket assembly, the shield, and the superconducting magnets are the same as those developed in the ARIES-IV and PULSAR [10] tokamak reactor studies. However, there is no blanket directly under the helical windings on the inboard side of the torus in order to reduce $R_{0}$. The inboard half of the helical winding with its side shields 


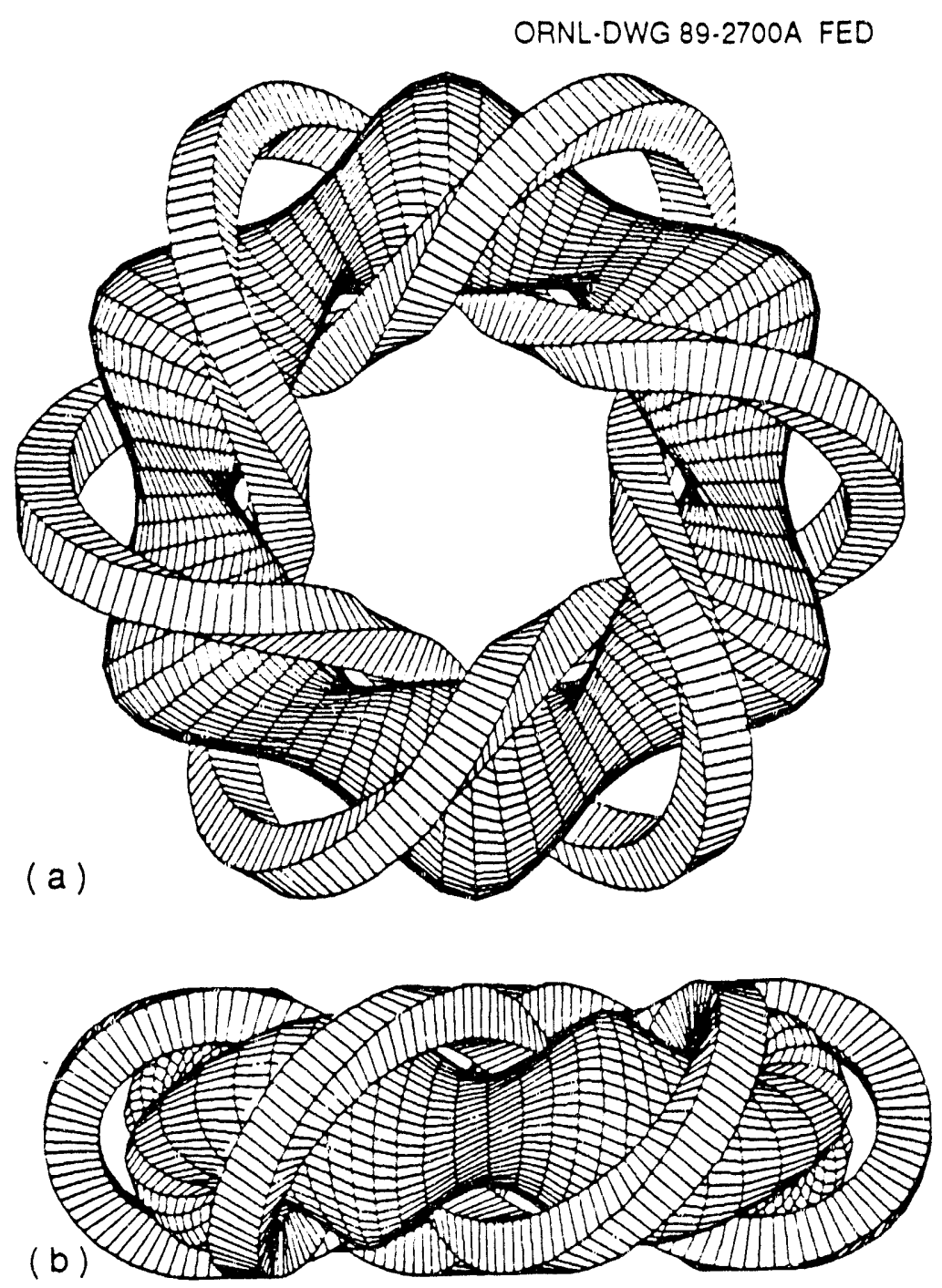

Fig. 1. (a) Top and (b) side views of the helical windings and the last closed flux surface for the CT6 configuration. There are also two VF coils (included in calculations) that are not shown.

typically covers $-20 \%$ of the first-wall area. The loss in the global tritium breeding can be compensated by increasing the thickness of the blanket elsewhere and/or increasing the beryllium fraction. In this study, the thickness of the blanket elsewhere is increased to $80 \mathrm{~cm}$ (vs $35 \mathrm{~cm}$ on the inboard side and $60 \mathrm{~cm}$ on the outboard side for ARIES-IV), as indicated in Table 1.

The fixed components that lie between the face of the superconducting winding pack and the edge of the plasma are the coil cryostat, the vacuum vessel wall, the multicomponent shield (lead, $\mathrm{TiH}_{1.8}$, and $\mathrm{SiC}$ ), a multicomponent $\left(\mathrm{Li}_{2} \mathrm{O}, \mathrm{SiC}, \mathrm{Be}, \mathrm{He}\right)$ blanket module, and the first wall. There are also gaps between the cryostat and the vacuum vessel wall, between 


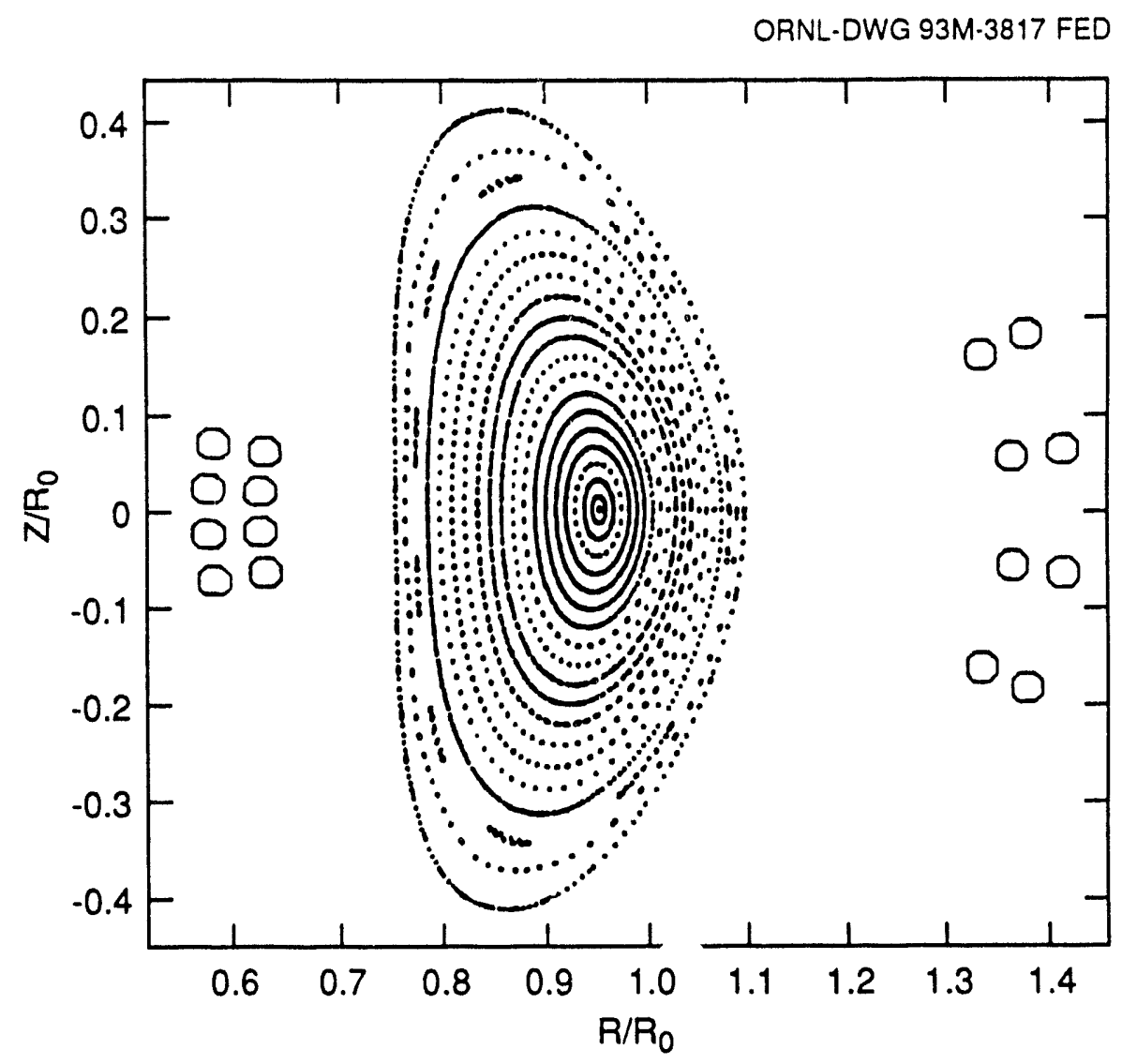

Fig. 2. A vertical cross section of the helical windings (here represented by eight current filaments) and magnetic flux surfaces for CT6 at the beginning of a field period.

Table 1. Dimensions of the components in the radial build for the reference CT6 and ARIES-IV reactors

\begin{tabular}{|c|c|c|c|}
\hline Radial build component & $\begin{array}{l}\text { Thickness under } \\
\text { inboard HF (m) }\end{array}$ & $\begin{array}{l}\text { Thickness } \\
\text { elsewhere (m) }\end{array}$ & $\begin{array}{l}\text { Thickness in } \\
\text { ARIES-IV (m) } \\
\text { inboard/outboard }\end{array}$ \\
\hline Coil cryostat & 0.05 & 0.05 & 0.05 \\
\hline Clearance & 0.05 & $0.05+0.60$ & 0.05 \\
\hline Vacuum vessel wall & 0.10 & 0.10 & 0.10 \\
\hline Gap & 0.02 & 0.02 & 0.02 \\
\hline Shield $\left(\mathrm{SiC} / \mathrm{TiH}_{1.8} / \mathrm{Pb}\right)$ & 1.00 & 0.75 & 0.95 \\
\hline Gap & 0.02 & 0.02 & 0.02 \\
\hline Blanket $\left(\mathrm{Li}_{2} \mathrm{O} / \mathrm{SiC} / \mathrm{Be} / \mathrm{He}\right)$ & 0 & 0.80 & $0.35 / 0.60$ \\
\hline First wall & 0.01 & 0.01 & 0.01 \\
\hline Plasma scrapeoff layer & 0.05 & 0.05 & 0.05 \\
\hline Total & 1.3 & $1.8+0.6$ & 1.6 \\
\hline
\end{tabular}


the shield and the vacuum vessel wall, between the shield and the blanket, and the scrape-off region between the plasma edge and the first wall. The thicknesses of these components for the CT6 reactor are compared with those for the ARIES-IV reactor in Table 1. The additional 0.6-m gap between the vacuum vessel wall and the coil cryostat under the outboard half of the helical field (HF) winding results from the fact that the plasma is farther from the HF winding on the outboard side, as can be seen from fig. 2.

The blanket and shield components, developed during the ARIES-IV and PULSAR studies, were chosen for their low activation properties. The $\mathrm{TiH}_{1.8}$ shield makes the shielding effectiveness of the ceramic shield comparable to that of a metallic shield. The blanket is assumed to have a global tritium breeding ratio of 1.12 and an energy multiplication factor of 1.3. The shield thickness of $1 \mathrm{~m}$ around the helical winding on the inboard side of the torus is the minimum allowable. A factor of 10 extra shielding (including that produced by the blanket) is provided elsewhere to keep the total magnet heating to a reasonable level.

The coils, like those in ARIES, use $\mathrm{Nb}_{3} \mathrm{Sn}$ superconducting cables with a partially loadbearing CuNb stabilizer [5]. The superconducting winding pack, which includes the superconducting cables, helium coolant paths, and structure, is assumed to have a rectangular cross section with transverse (mainly toroidal) elongation $k=h / w$, where $h$ and $w$ are half the transverse width and half the radial depth of the helical winding pack, respectively. The maximum magnetic field on the superconductor, $B_{\max }$, is calculated from an expression that gives an excellent fit over a wide range of coil configurations to results obtained using a finite-element code with accurate helical winding trajectories. As in the ARIES studies, the volume of the coil support structure is half that of the coils. The divertor area required is calculated by dividing the total power to the divertor by $3 \mathrm{MW} \cdot \mathrm{m}^{-2}$. The other engineering and materials assumptions are the same as those for ARIES-IV.

\subsection{TRANSPORT ASSUMPTIONS}

Different scalings for the global energy confinement time $\tau_{E}$ fit present stellarator data: (1) the Large Helical Device (LHD) scaling [11],

$$
\tau_{E^{\mathrm{LHD}}}^{\mathrm{LHD}}=0.17 R_{0}{ }^{0.75} a_{\mathrm{p}}{ }^{2} n^{0.69} B_{0} 0.84 P^{0.58},
$$

an empirical fit to stellarator data; (2) the gyro-reduced Bohm scaling [12],

$$
\tau_{E^{\mathrm{grB}}}=0.25 B_{0} 0.8 n^{0.6 P-0.6} a_{\mathrm{p}}{ }^{2.4} R_{0} 0.6,
$$

which is based on drift-wave theory; and (3) the Lackner-Gottardi scaling [13],

$$
\tau_{E}{ }^{\mathrm{LG}}=0.17 R_{0} a_{\mathrm{p}}{ }^{2} n^{0.6} B_{0} 0.8 P-0.6 \chi^{0} 0.4,
$$

which fits both tokamak and stellarator data. Here $B_{0}$ is the on-axis field, $n$ is the lineaveraged electron density (in $10^{20} \mathrm{~m}^{-3}$ ), $P$ is the absorbed heating power (in $\mathrm{MW}$ ), and $\chi(=1 / q$, where $q$ is the tokamak safety factor $)$ is the rotational transform. All other quantities are in SI units. Stellarators and tokamaks have similar energy confinement time scaling, 
indicating that the underlying physics may be dominated by common toroidal plasma physics rather than coil-geometry-specific effects.

Unlike the LHD scaling, the Lackner-Gottardi scaling and the gyro-reduced Bohm scaling are dimensionally correct; that is, they are expressible in terms of dimensionless plasma parameters. In addition, they have the same functional dependence on the reactor parameters $R_{0}, B_{0}, n$, and $P$, differing only by an aspect-ratio-dependent coefficient; for the torsatron reactor examples studied in this paper, $\tau_{E} \mathrm{LG}=0.95 \tau_{E} \mathrm{grB}$. Coincidentally, the Lackner-Gottardi and LHD scalings give almost the same value of $\tau_{E}$ for typical reactor cases, even though they have different functional dependences on the reactor parameters.

For this paper we choose Lackner-Gottardi scaling with a confinement improvement factor $\mathrm{H}^{\prime}$ similar to the $\mathrm{H}$-mode confinement improvement factor for tokamaks. Evidence from experiments and theoretical arguments support such a confinement improvement. However, the improvement with the square root of the ion mass used in tokamak scaling is not assumed in our study, and $\chi$ is evaluated at a normalized radius $\rho=r / a_{\mathrm{p}}=2 / 3$, rather than at the plasma edge; reversing either of these assumptions would improve the confinement time by a factor of $1.2-1.3$.

The maximum plasma density in stellarators is not determined by a disruption limit as in tokamaks. Sudo et al. [11] have proposed a maximum line-average density,

$$
n_{\max }=0.25\left(P B_{0} / R_{0} a_{\mathrm{p}}^{2}\right)^{1 / 2}
$$

based on Heliotron E data. Densities a factor of 1.3 higher than this value have been observed in the Advanced Toroidal Facility (ATF). For this study, we assume that the line-average density is constrained to $<1.5 n_{\max }$.

\subsection{TRANSPORT MODEL}

One-dimensional (1-D) heat transport equations are solved for the ion and electron temperatures $T_{\mathrm{i}}(\rho)$ and $T_{\mathrm{e}}(\rho)$ using a heat diffusivity $\chi(\rho)=\chi 0 /\left(1-\alpha \rho^{2}\right)$ to simulate the radial variation of $\chi$ seen in experiments. The constants $\chi_{0}$ and $\alpha$ are chosen to give an energy confinement time $\tau_{E}=H^{\prime} \tau_{E}{ }^{L G}$; the reference assumptions are $H^{\prime}=2$ and $\alpha=0.9$ (a factor of 10 increase in $\chi$ from the center to the edge of the plasma). The internal heat sources and sinks include alpha-particle heating, bremsstrahlung and synchrotron radiation, and electron-ion Coulomb collisions. Impurities are modeled by $1 \%$ oxygen, giving a deuterium-tritium (D-T) fuel fraction $n_{\mathrm{DT}} / n_{\mathrm{e}}=0.92$ and an effective ionic charge $Z_{\text {eff }}=1.56$. The density profile used is the same as that assumed in the ARIES studies, $n=$ $n_{0}\left[\left(1-n_{\mathrm{S}} / n_{0}\right)\left(1-\rho^{2}\right)^{\alpha_{n}}+n_{\mathrm{S}} / n_{0}\right]$; the reference values are $\alpha_{n}=1.0$ and $n_{\mathrm{S}} / n_{0}=0.538$.

\subsubsection{Alpha-Particle Losses}

Because the relatively large helical ripple in torsatrons, combined with symmetrybreaking toroidal effects, can lead to a near-perpendicular loss region for energetic particles, we assume that all helically and toroidally trapped alpha particles are lost and calculate the additional energy lost by passing particles that pitch-angle scatter into the loss region during 
the slowing-down process. The combined loss can reduce the effective alpha-particle heating by up to $-40 \%$. Most of the alpha particles are not born in the loss region and transfer their energy to the background plasma until they slow down to an energy $W=30 T_{\mathrm{e}} \sim 0.3-1 \mathrm{MeV}$, below which they rapidly scatter into the loss region [3]. This loss can produce an intense flux of energetic alpha particles on the divertor plates. The loss of alpha-particle heating is offset by increased fusion power ( $\propto n_{\mathrm{DT}}{ }^{2} / n_{\mathrm{e}}{ }^{2}$ at a given temperature) because the loss region prevents accumulation of helium ash and the dilution of the D-T fuel, as shown in Table 2. The positive and negative effects usually balance each other, as shown later in the paper.

\subsection{BETA LIMITS}

There is no analog in stellarators to the simple tokamak Troyon beta limit. Threedimensional magnetohydrodynamic (MHD) calculations of the maximum permissible volume-average beta $\langle\beta\rangle$ indicate that $\langle\beta\rangle-4 \%$ should be attainable in properly designed stellarators. This value is used as an upper limit in this study, but the optimum beta is usually significantly below this value.

\subsection{REACTOR OPTIMIZATION}

The quantity minimized in the reactor optimization approach is the projected cost of electricity $(\mathrm{COE})$. The masses of the individual reactor components are used to calculate the cost of the reactor core, using the cost models established for the ARIES studies $[4,5,9]$. The expressions used for the other elements of the reactor cost and the COE are those used in the ARIES-IV study [9]. The plant availability factor is taken to be 0.76 , the same as in the ARIES tokamak reactor studies, although stellarator reactors could have a higher availability because of the absence of both disruptions and the need for continuous current drive. This difference could be significant because the COE is inversely proportional to the availability. As in the ARIES studies, the costs assume "learning curve" credits of $\approx 50 \%$ associated with a "tenth-of-a-kind" reactor. These credits, plus the level of safety assurance (LSA) factors [14] appropriate to the safety and enviromental advantages of the ARIES and PULSAR designs, result in a COE that is competitive with that for tokamak reactors. The LSA scale varies from

Table 2. Effect of helium ash accumulation on reactor parameters

\begin{tabular}{|c|c|c|}
\hline Property & With $40 \%$ loss region & With no loss region \\
\hline Helium fraction $n_{\mathrm{He}} / n_{\mathrm{e}}$ & 0 & 0.1 \\
\hline Fuel fraction $n_{\mathrm{DT}} / n_{\mathrm{e}}$ & 0.92 & 0.72 \\
\hline Relative fusion power & 1 & 0.61 \\
\hline $\begin{array}{l}\text { Relative plasma heating (including } \\
\text { orbit losses) }\end{array}$ & 0.60 & 0.61 \\
\hline Fuel-ion $\langle\beta\rangle$ for $4 \%$ total $\langle\beta\rangle$ & $4 \%$ & $3.1 \%$ \\
\hline$Z_{\text {eff }}$ & 1.6 & 1.8 \\
\hline Relative radiation losses & 0.89 & 1 \\
\hline
\end{tabular}


1 to 4 with $\mathrm{LSA}=1$ (assumed here) being inherently safe and LSA $=4$ requiring active engineered safeguards, as in present fission plants.

The optimization variables are those related to the device size $\left(R_{0}\right)$, the resulting plasma parameters (volume-averaged density $\langle n\rangle$, density-averaged temperature $\langle T\rangle$ ), and the magnetic field ( $B_{0}$ and the transverse width and radial depth of the helical winding pack). The reference constraints chosen for the optimization are net electric power $P_{E}=1 \mathrm{GW},\langle\beta\rangle \leq$ $4 \%, n \leq 1.5 n_{\max }$, and a set of helical winding constraints [radial distance between the edge of the plasma and the center of the HF winding on the inboard side, clearance between the HF windings for access, $k \leq k_{\max }=3, B_{\max } \leq 16 \mathrm{~T}$, and limits on the current density in the winding pack, $j \leq j_{\max }=50 \mathrm{MA} \cdot \mathrm{m}^{-2}$ ]. As with the value of beta, the optimum values of $B_{\max }$ and $j$ are not necessarily these upper limiting values. However, the optimization almost always leads to $k=k_{\max }$ (which reduces $w$, and hence $R_{0}$ and the COE) and to $n=1.5 n_{\max }$, [which also reduces $R_{0}$ through eq. (4)].

The COE is minimized when $R_{0}$ is minimized because the cost of the most expensive components, the constant-thickness blankets and shields, varies as $R_{0}{ }^{2}$. The minimum value for $R_{0}$ is set by the need for a certain distance between the plasma edge and the center of the helical winding for half the thickness of the coil winding pack, $w$, plus the total thickness $d$ of the plasma-wall separation, the first wall, the blanket, the shield, the vacuum vessel wall, and the cryostat, as indicated in Table 1. Figures 1 and 2 show that the space between the plasma edge and the helical winding on the inboard half of the torus is the determining distance; the space on the outboard half of the torus is more than adequate. The minimum distance $\Delta$ between the edge of the plasma (the last closed flux surface) and the centerline of the helical winding or modular coil determines the minimum size for a stellarator reactor because the ratio $A_{\Delta} \equiv R_{0} / \Delta$ is a constant for a given stellarator coil configuration $\left(A_{\Delta}=6.37\right.$ for CT6). The minimum value possible for $R_{0}$ is thus $A_{\Delta}(d+w)$ because $\Delta$ must be $\geq(d+w)$.

Minimizing the radial depth of the winding pack and the thickness of the blanket and shield under the inboard half of the helical winding, as well as $A_{\Delta}$, is important in reducing the cost of stellarator reactors because the cost increases with $R_{0}$. The smaller value of $A_{\Delta}$ obtained in Compact Torsatrons allows $R_{0}$ for this type of reactor to be a factor of $\approx 2$ smaller than for modular stellarator reactors; typically $R_{0} \approx 10 \mathrm{~m}$ vs $R_{0} \approx 20 \mathrm{~m}$. 


\section{COMPARISONS WITH ARIES TOKAMAK REACTORS}

\subsection{COMPARISON OF PLASMA PARAMETERS}

The main plasma parameters obtained for the COE-optimized CT6 reference case are compared in Table 3 with those for ARIES-I', a first-stability tokamak reactor, and ARIES-IV, a second-stability tokamak reactor [15]. The CT6 reference case is an updated version of an earlier CT6 reactor [16] based on a 0-D transport model and a much thinner blanket and shield under the inboard half of the helical windings. The ARIES-I' case is ARIES-I recalculated with the improved blanket and shield models developed in the ARIES-IV studies. When ARIES-I was recalculated [16] with the stellarator reactor code to benchmark our calculations and to provide a more detailed comparison with the torsatron reactor calculations, the values obtained were very close (a few tenths of a percent) to the valucs obtained in a May 1992 recalculation of ARIES-l. The slight differences arose from the different approximations used in calculating the masses of the blankets and shields.

The larger major radius and plasma aspect ratio for CT6 lead to a plasma volume 2-2.8 times that of ARIES-I' and ARIES-IV, respectively; this allows a lower value of the average temperature for the same power output. The density-averaged temperature $\langle T\rangle$ is only 0.39-0.77 that for the ARIES cases. The larger ratio of central ion temperature to $\langle T\rangle$ is due to the fact that the temperature profile calculated for CT6 is more peaked than that assumed for the ARIES cases, as discussed in Sect. 4.1. The beta for ARIES-I' is constrained to a lower value by the modest plasma current (10.9 MA) and the high central magnetic field

Table 3. Main plasma parameters for reference CT6 torsatron and ARIES tokamak reactors

\begin{tabular}{llll}
\hline & CT6 & ARIES-I' & ARIES-IV \\
\hline Major radius $R_{0}(\mathrm{~m})$ & 10.03 & 7.64 & 6.04 \\
Average plasma radius $a_{\mathrm{p}}(\mathrm{m})$ & 2.66 & 2.28 & 2.15 \\
Plasma ellipticity $\kappa$ & 2.1 & 1.8 & 2.0 \\
Plasma volume $\left(\mathrm{m}^{3}\right)$ & 1400 & 710 & 500 \\
Plasma current $(\mathrm{MA})$ & 0 & 10.9 & 6.6 \\
Bootstrap current fraction & $-\ldots . .-$ & 0.68 & 0.87 \\
Edge safety factor $q$ & 1.05 & 4.5 & 12.2 \\
Average electron density $\langle n\rangle\left(10^{20} \mathrm{~m}^{-3}\right)$ & 1.30 & 1.26 & 2.90 \\
Average plasma temperature $\langle T\rangle(\mathrm{keV})$ & 7.7 & 20 & 10 \\
Central ion temperature $(\mathrm{keV})$ & 24.6 & 38.0 & 26.5 \\
Volume-average toroidal beta $(\%)$ & 3.1 & 1.9 & 3.4 \\
Fraction of alpha-particle power lost & 0.42 & 0 & 0.035 \\
Fraction of plasma power radiated & 0.31 & 0.50 & 0.23 \\
Energy confinement time $\tau_{\mathrm{E}}(\mathrm{s})$ & 4.6 & 2.9 & 1.5 \\
Plasma $\mathrm{Q}$ value & $\infty$ & 18 & 30 \\
\hline
\end{tabular}


(10.6 T) through the tokamak Troyon beta limit. A larger multiplier for the Troyon beta limit allows a higher $\langle\beta\rangle$ value for ARIES-IV. The most noticable difference is in the fraction of alpha-particle power lost and the plasma $Q$ value. In most respects, the CT6 case is closer to ARIES-IV than to ARIES-I'.

\subsection{COMPARISON OF DEVICE PARAMETERS}

Table 4 gives the main device parameters for CT6 and the ARIES-I' ${ }^{\prime}$ and ARIES-IV tokamak reactors. The field on axis for CT6 is one-half to two-thirds of that in the ARIES cases, but the maximum field on the helical windings is similar to that on the TF coils in ARIES-IV, as is the total stored magnetic energy and the mass of the VF coils. ARIES-I' has significantly larger values for these quantities. The mass of the CT6 helical winding is a factor of 1.6-3.1 lower than the mass of the ARIES TF coils because the CT6 coil perimeter is smaller (the winding is closer to the plasma) and the cross section is much smaller (similar or less total ampere-turns and higher average current density because of the lower magnetic field). The primary reason for the lower current density in the ARIES cases is the larger amount of internal structure needed for the hoop force. The mass of the accompanying coil support structure is also much smaller for CT6. The neutron wall loading is a factor of 1.7-2.3 smaller than that in the ARIES cases because of the larger CT6 wall area and the smaller required fusion power. The fusion power, thermal power, gross electric power, and recirculating power fraction are more for the ARIES cases because of the tokamak's current drive requirement. The total mass of the CT6 fusion power core (FPC) is 8,870 tonnes vs

Table 4. Main device parameters for reference CT6 torsatron and ARIES tokamak reactors

\begin{tabular}{|c|c|c|c|}
\hline & CT6 & ARIES-I' & ARIES-IV \\
\hline Toroidal field on axis $(\mathrm{T})$ & 5.0 & 10.6 & 7.6 \\
\hline Maximum field on coils $B_{\max }(\mathrm{T})$ & 16.0 & 19.1 & 15.9 \\
\hline $\mathrm{HF} / \mathrm{TF}$ coil current density $j\left(\mathrm{MA} / \mathrm{m}^{2}\right)$ & 46.4 & 24.5 & 30.0 \\
\hline Magnetic field energy (GJ) & 86 & 213 & 93 \\
\hline Mass of HF/TF coils (tonnes) & 1330 & 4180 & 2130 \\
\hline Mass of VF coils (tonnes) & 630 & 930 & 610 \\
\hline Current-drive power (MW) & 0 & 115 & 68 \\
\hline Fusion power (MW) & 1760 & 2040 & 2020 \\
\hline Neutron wall loading $\Gamma_{\mathrm{n}}\left(\mathrm{MW} / \mathrm{m}^{2}\right)$ & 1.18 & 2.06 & 2.67 \\
\hline Thermal power (MW) & 2240 & 2600 & 2530 \\
\hline Gross electric power $[\mathrm{MW}(\mathrm{e})]$ & 1100 & 1270 & 1240 \\
\hline Recirculating power percentage (\%) & 9 & 21 & 19 \\
\hline Net electric output [MW(e)] & 1000 & 1000 & 1000 \\
\hline Mass power density [kW(e)/tonne] & 113 & 72 & 111 \\
\hline Cost of electricity [mill/kW(e)h] $]^{(a)}$ & 65.6 & 76.6 & 67.7 \\
\hline
\end{tabular}

(a) In constant 1992 dollars. 
13,900 tonnes for ARIES-I' and 9,100 tonnes for ARIES-IV, resulting in a higher mass utilization efficiency and a lower COE for the CT6 case.

The total reactor equipment cost (whose elements are shown in Table 5) for CT6 is $9 \%$ more than that for ARIES-IV and 19\% less than that for ARIES-I'. The main differences are the larger cost for the CT6 blanket (because of its larger thickness and the larger wall area) and the lower costs for the magnets (and the related primary support and structure) and the supplemental heating systems (only needed for plasma startup). The geometry-dependent FPC components (blanket and first wall, divertor, shields, magnets, vacuum vessel, and primary structure) are $74 \%$ of the $\$ 1410 \mathrm{M}$ total reactor plant equipment cost and $50 \%$ of the $\$ 2070 \mathrm{M}$ total direct cost for CT6; components that depend on the hermal and electrical power make up the remainder. The $\$ 3860 \mathrm{M}$ total capital cost for $\mathrm{C}^{\prime} \mathrm{l}^{\prime} 6$ is 1.87 times the total direct cost because of financial charges that are proportional to the total direct cost. The difference in the COE for CT6 and ARIES-IV is due to the smaller blanket and first-wall replacement costs for CT6 (longer lifetime because of the lower neutron flux and a different blanket replacement algorithm). A large part of the $17 \%$ difference in the COE between CT6 and ARIES-I' ${ }^{\prime}$ is due to the $14 \%$ larger capital cost for ARIES-I'.

Table 5. Costs of reactor equipment for reference CT6 torsatron and ARIES tokamak reactors

\begin{tabular}{lccc}
\hline & \multicolumn{3}{c}{ Costs $^{(a)}(\mathrm{M} \$)$} \\
\cline { 2 - 4 } Item & CT6 & ARIES-I & ARIES-IV \\
\hline First wall, blanket, and reflector & 258 & 105 & 87 \\
Shields & 525 & 516 & 407 \\
Magnets & 164 & 437 & 223 \\
Supplemental heating systems & 49 & 155 & 176 \\
Primary structure and support & 20 & 71 & 37 \\
Reactor vacuum systems & 66 & 62 & 53 \\
Power supply, switching, storage & 50 & 50 & 50 \\
Impurity control & 6 & 12 & 6 \\
ECH breakdown system & 0 & 4 & 4 \\
Total reactor equipment & 1138 & 1411 & 1041 \\
\hline
\end{tabular}

(a) In constant 1992 dollars. 


\section{SENSITIVITY OF THE REFERENCE CT6 CASE TO TRANSPORT ASSUMPTIONS}

\subsection{RADIAL PROFILES FOR THE REFERENCE CT6 CASE}

Figure 3 shows the radial profiles obtained for the electron and ion temperatures and the assumed (ARIES) density profile for the optimized CT6 reference case. The temperature profiles would be parabolic if $n, \chi$, and the power to the electrons and ions $\left(p_{e, i}\right)$ were constant with radius. The profiles are more peaked because $p_{\mathrm{e}, \mathrm{i}}$ increases with density and temperature (and hence decreases with radius) and $n \chi$ increases with radius.

The dependence of the shape of the ion temperature profile on the shape of the density profile is illustrated in figs. 4 and 5 for parabolic density profiles as the ratio of the edge density to the central density, $n(1) / n(0)$, is varied from 0.1 to 1 . The broad density profiles typically seen in stellarators lead to peaked temperature profiles. However, the pressure profile $\left(\propto n_{\mathrm{e}} T_{\mathrm{e}}+n_{\mathrm{i}} T_{\mathrm{i}}\right)$ is relatively insensitive to these variations in the density profile, as shown in fig. 6 , and there is only a $3 \%$ variation in the $\mathrm{COE}$ from the flattest density profile to the most peaked. The heat flux equations can be written approximately in terms of the variable $n T$ with a smaller term proportional to $\nabla n$ because the alpha-particle heating term is dominant and varies approximately as $n^{2} T^{2}$. This leads to the relative insensitivity of the pressure profile to the assumed form for the density profile.

ORNL-DWG 94M-2201 FED

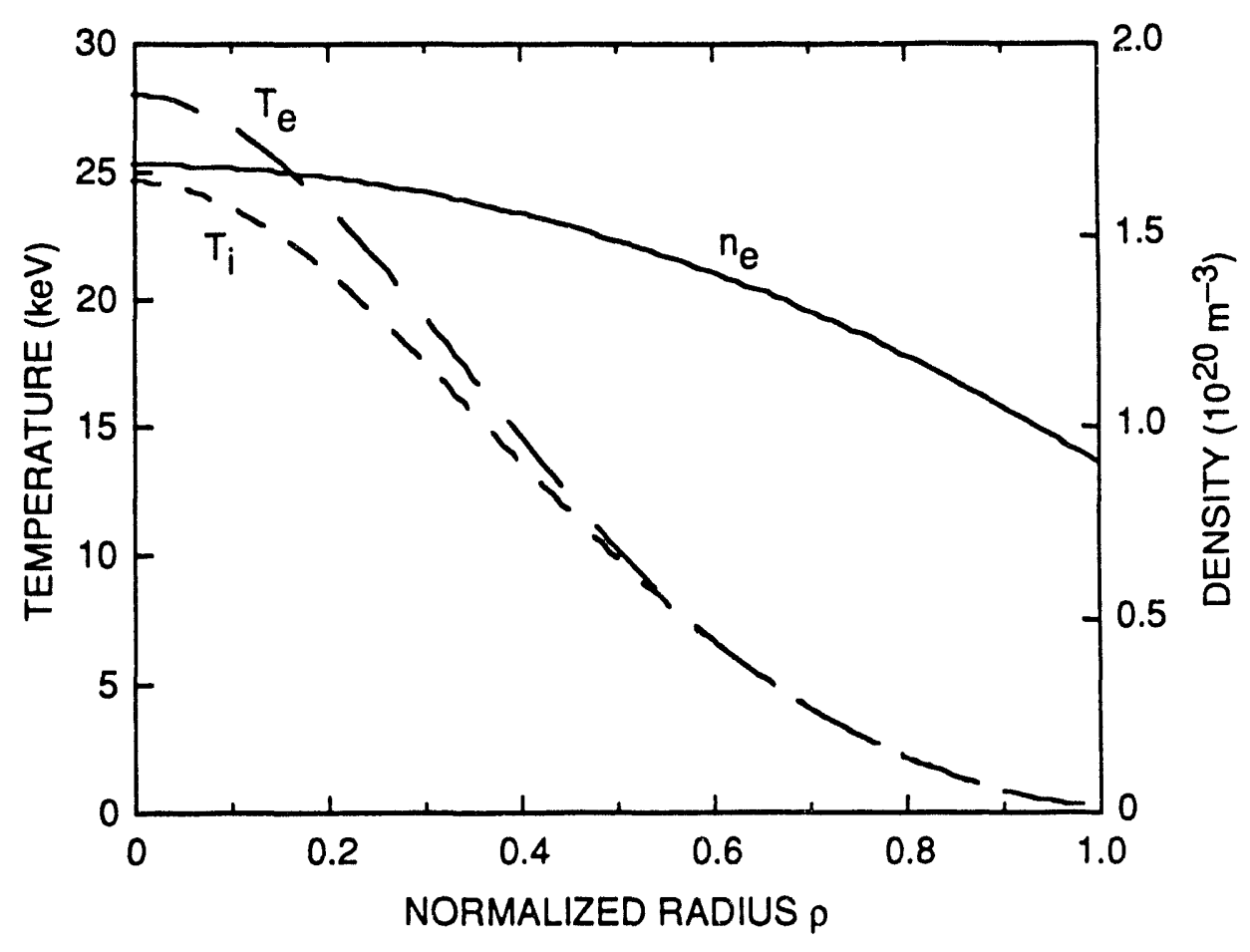

Fig. 3. Electron and ion temperature and density profiles for the CT6 reference case. 


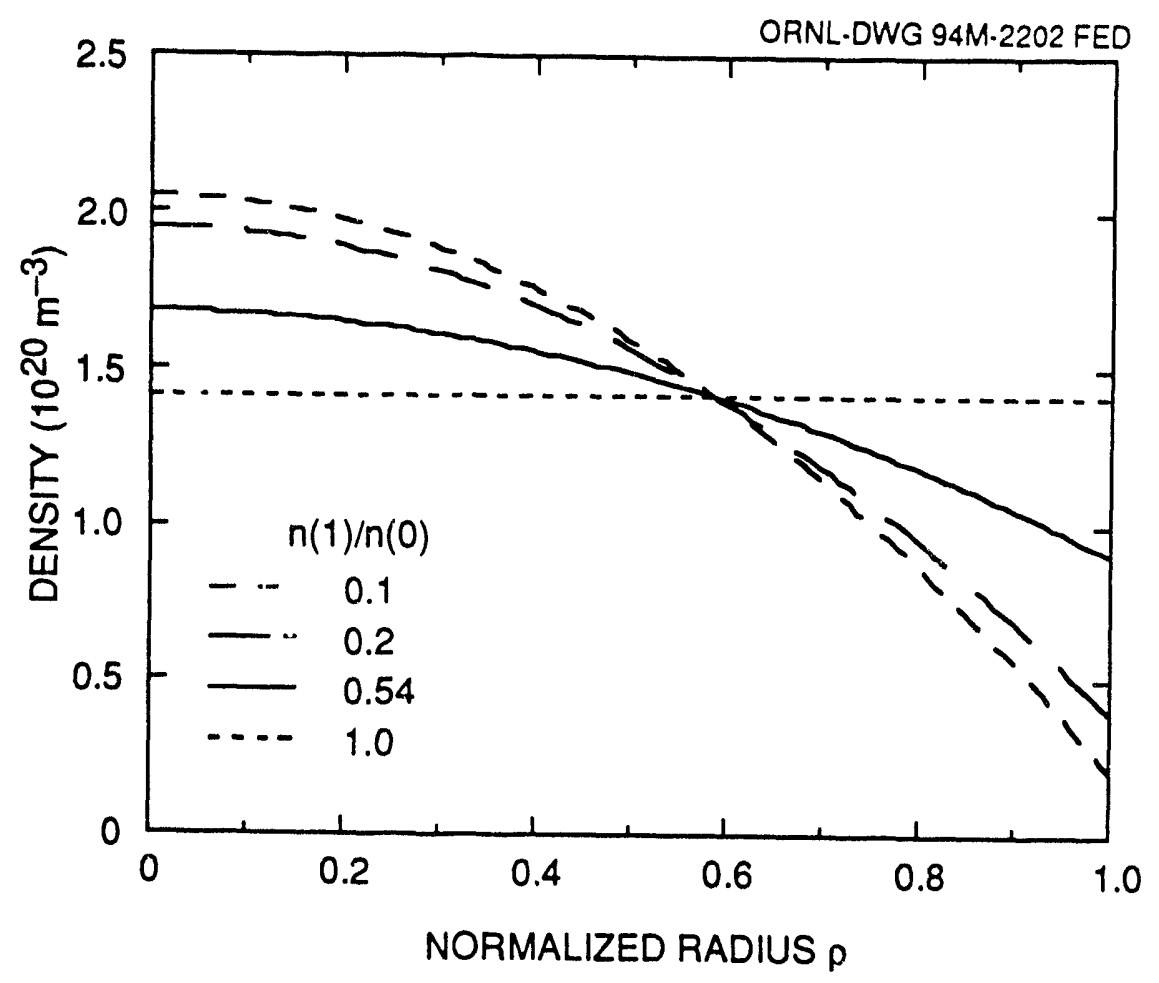

Fig. 4. Plasma density profiles assumed in this study.

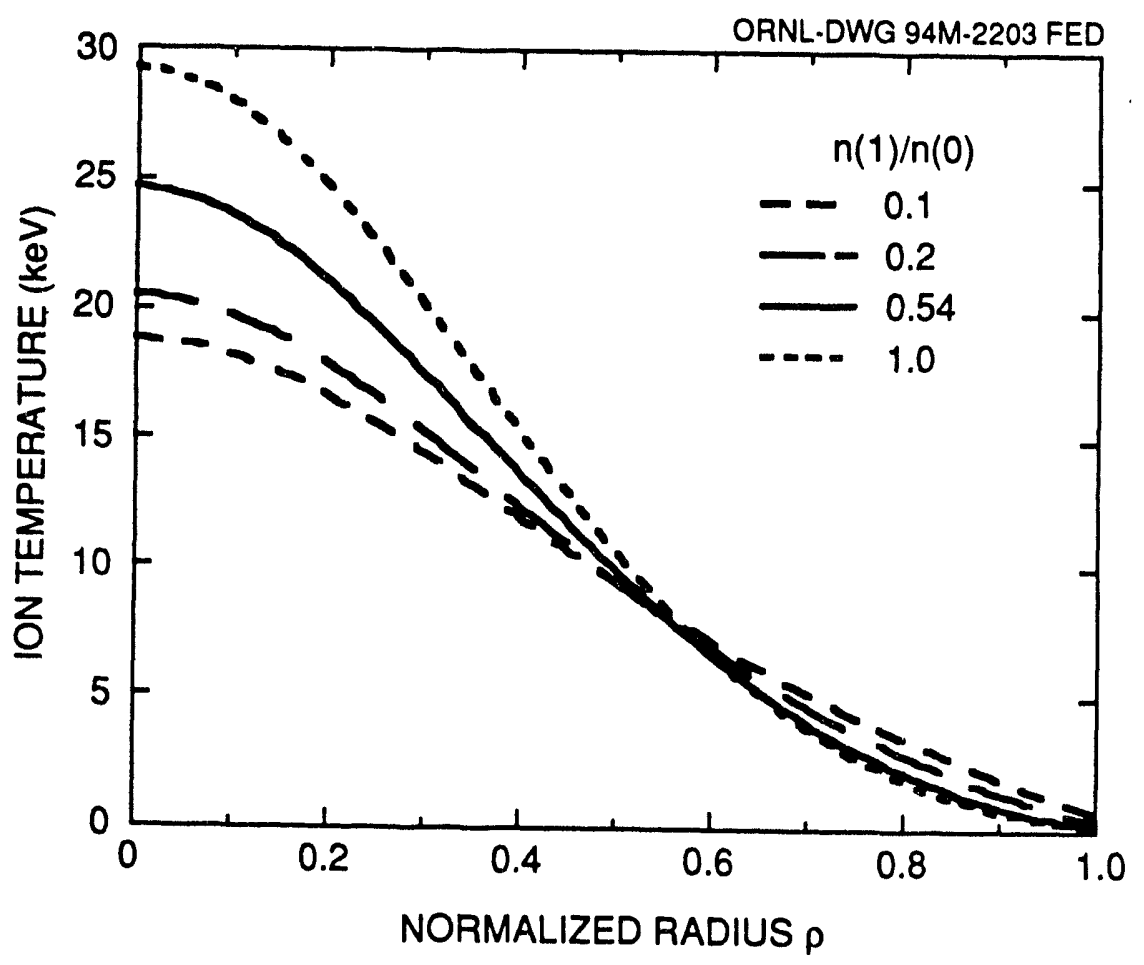

Fig. 5. Ion temperature profiles for different assumed density profiles. 


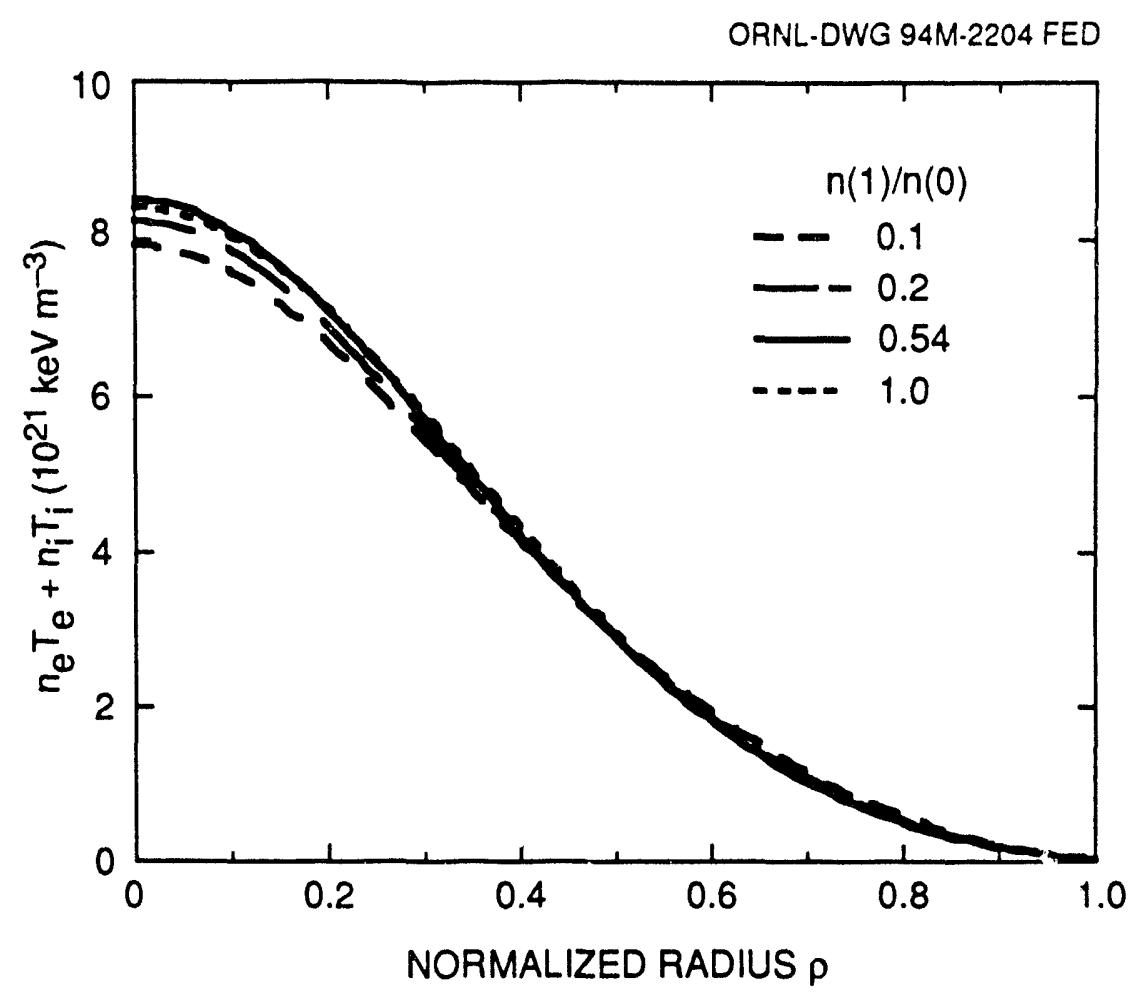

Fig. 6. Plasma pressure profiles for different assumed density profiles for the reference case.

Figure 7 shows the variation in the ion temperature profile as the coefficient $\alpha$ in $\chi(\rho)=$ $\chi 0 /\left(1-\alpha \rho^{2}\right)$ is varied: $\alpha=0.67$, so $\chi(1) / \chi(0)=3 ; \alpha=0.9$, so $\chi(1) / \chi(0)=10$; and $\alpha=0.967$, so $\chi(1) / \chi(0)=30$. The ion temperature profiles in figs. 5 and 7 are lower at the outside and higher in the center when $n \chi$ is higher at the edge of the plasma. There is also only a $3 \%$ variation in the $\mathrm{COE}$ in this case from one extreme to the other.

The electron and ion temperatures affect the power balance in different ways: the fusion power production only depends on $T_{\mathrm{i}}$, while the alpha-particle power lost, the relative power transfer to the ions and electrons, and the radiation losses only depend on $T_{\mathrm{e}}$. The balance between $T_{\mathrm{i}}$ and $T_{\mathrm{e}}$ can be changed by changing the ratio of the ion and electron thermal diffusivities, as indicated in Table 6 . As $\chi_{\mathrm{i}} / \chi_{\mathrm{e}}$ increases, $T_{\mathrm{i}}$ drops relative to $T_{\mathrm{e}},\langle\beta\rangle$ decreases despite the increase in $\langle T\rangle$ because of the increase in $B_{0}$, and $R_{0}$ increases slightly. The net effect is a relatively small increase (3.6\%) in the COE for a large (factor of 9 ) variation in the ratio $\chi_{i} / \chi_{\mathrm{e}}$.

\subsection{SENSITIVITY TO CONFINEMENT IMPROVEMENT}

Figures 8 and 9 show the variation of the plasma and device parameters with $\mathrm{H}^{\prime}$. Improved energy confinement is reflected most strongly in the factor of 6 increase in $\langle\beta\rangle$, from $0.76 \%$ to $4.6 \%$, mostly due to the factor of 3.9 decrease in $B_{0}{ }^{2}$ and to a lesser extent to the factor of 2 decrease in the plasma volume (from $2580 \mathrm{~m}^{3}$ to $1310 \mathrm{~m}^{3}$ ), as $\mathrm{H}^{\prime}$ increases 


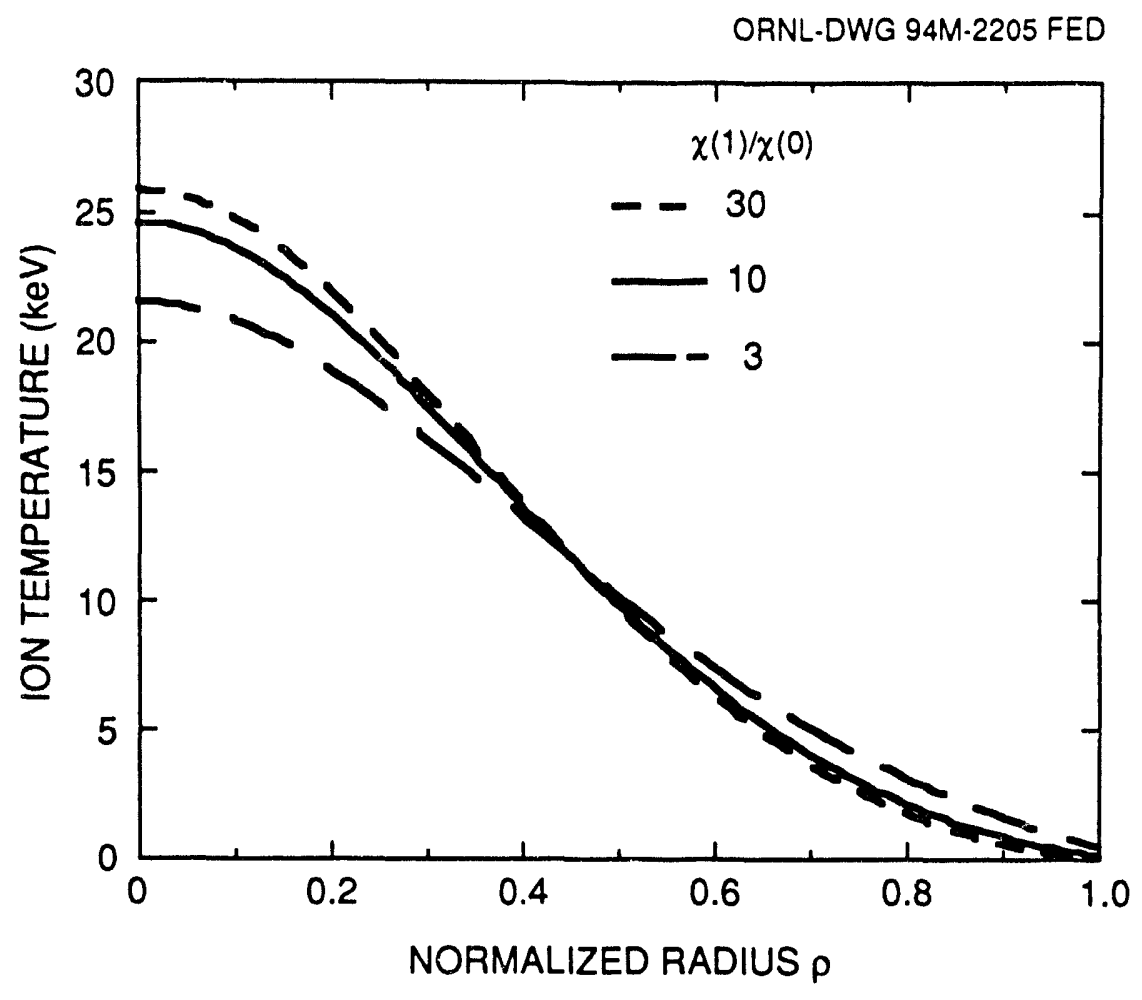

Fig. 7. Ion temperature profiles for different heat diffusivity profiles.

Table 6. Effect of relative ion and electron heat diffusivities on CT6 reactor parameters

\begin{tabular}{lccc}
\hline & $\chi_{\mathrm{i}} / \chi_{\mathrm{e}}=1 / 3$ & $\chi_{\mathrm{i}} / \chi_{\mathrm{e}}=1$ & $\chi_{\mathrm{i}} / \chi_{\mathrm{e}}=3$ \\
\hline Density-averaged temperature $\langle T\rangle(\mathrm{keV})$ & 7.52 & 7.69 & 7.98 \\
Central ion temperature $T_{\mathrm{i}}(0)(\mathrm{keV})$ & 27.0 & 24.6 & 23.8 \\
Central electron temperature $T_{\mathrm{e}}(0)(\mathrm{keV})$ & 25.7 & 28.0 & 32.4 \\
Volume-averaged density $\langle n\rangle\left(10^{20} \mathrm{~m}^{-3}\right)$ & 1.29 & 1.30 & 1.29 \\
Volume-averaged beta $\langle\beta\rangle(\%)$ & 3.37 & 3.09 & 2.99 \\
Major radius $R_{0}(\mathrm{~m})$ & 9.90 & 10.03 & 10.11 \\
Toroidal field on axis $B_{0}(\mathrm{~T})$ & 4.73 & 5.01 & 5.17 \\
Cost of electricity [mill/kW(e)h] & 64.5 & 6.0 & 66.8 \\
\hline
\end{tabular}

(a)In constant 1992 dollars. 


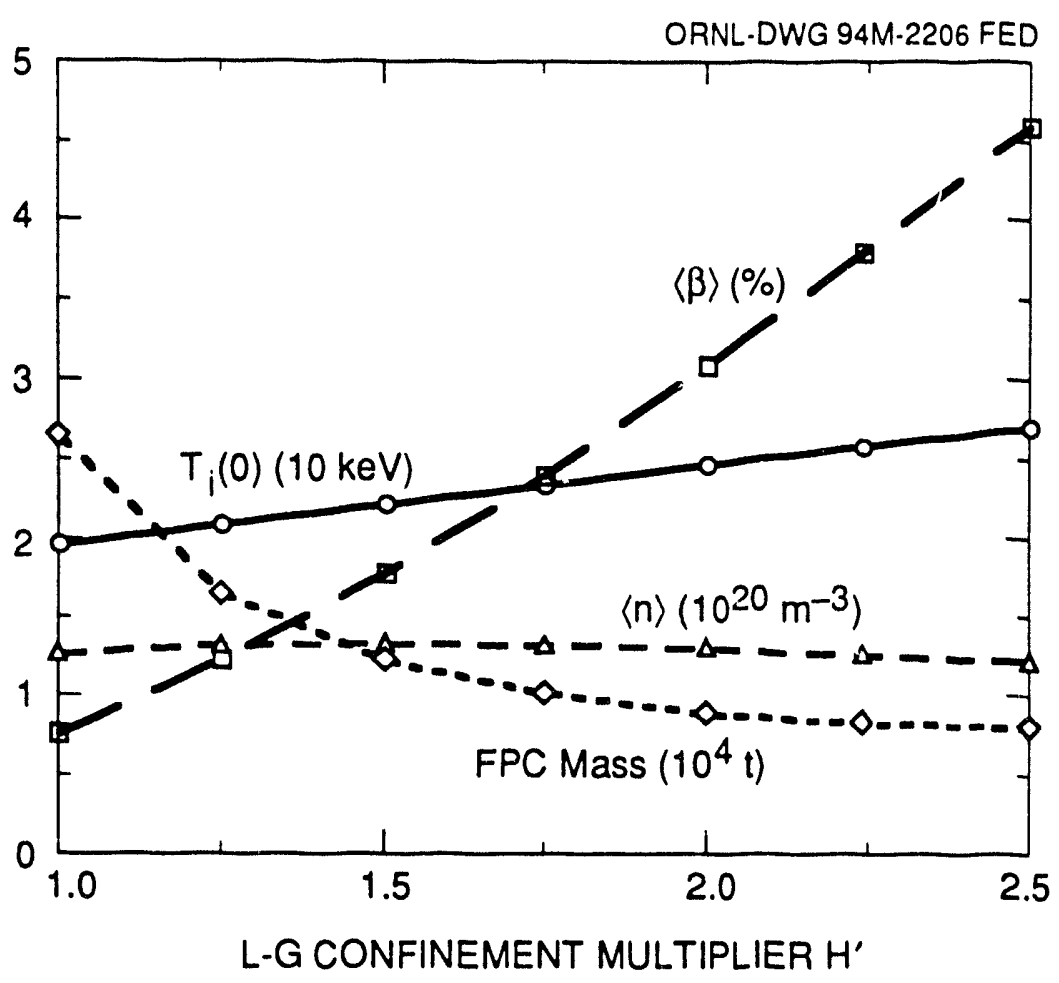

Fig. 8. Dependence of the reactor plasma parameters and the mass of the fusion power core on the Lackner-Gottardi confinement improvement factor $\mathrm{H}^{\prime}$.

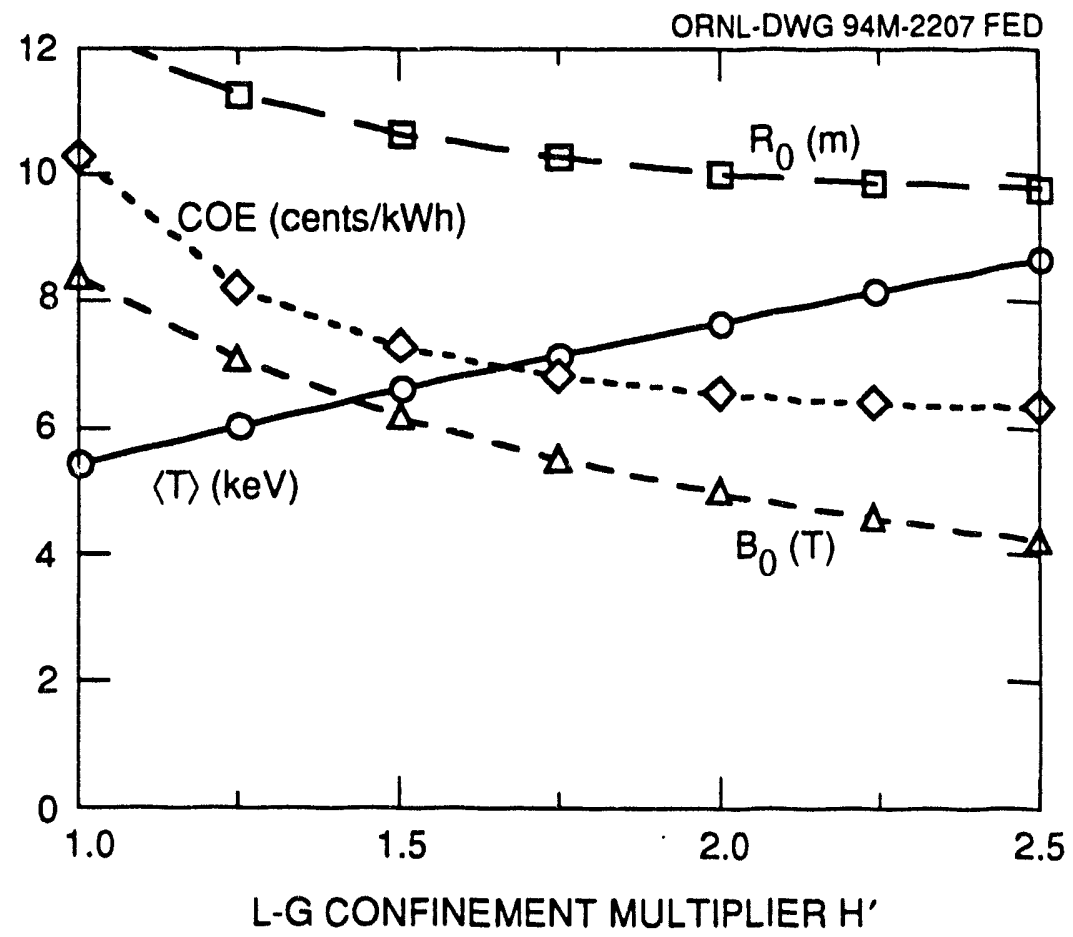

Fig. 9. Dependence of the reactor device parameters and the density-averaged temperature on the Lackner-Gottardi confinement improvement factor $\mathrm{H}^{\prime}$. 
from 1 to 2.5. The decreases in $B_{0}$ and $R_{0}$ are related because the minimum cost is obtained for the smallest $R_{0}$ (smallest plasma volume), so the plasma density must increase to its limit $\left(n_{\max } \propto B_{0} 1 / 2 / R_{0} 3 / 2\right.$, which is approximately independent of $\mathrm{H}^{\prime}$ from fig. 8 ) to keep the fusion power constant. In addition, the temperature must increase with increasing $\mathrm{H}^{\prime}$ to offset the decrease in the plasma volume and the increase in the scattered alpha-particle losses, which increase with $T_{\mathrm{e}}$. If the fusion power absorbed by the plasma varies as $\langle n\rangle^{2}\langle T\rangle^{\alpha} \mathrm{T}$, then eq. (4) gives $\langle T\rangle \propto B_{0} \alpha_{\mathrm{T}}$, independent of the other plasma and device parameters; in fig. 9 , $\langle T\rangle \propto B_{0}-1.5$. The ratio $T_{\mathrm{i}}(0) /\langle T\rangle$ varies slowly with $\mathrm{H}^{\prime}$, indicating that the ion temperature profile does not change significantly with $\mathrm{H}^{\prime}$.

The decrease in $R_{0}$ is due to the decrease in $w$. The mass of the FPC decreases continuously from 26,480 tonnes at $H^{\prime}=1$ to 7,970 tonnes at $H^{\prime}=2.5$. The rapid increase in the mass with decreasing $\mathrm{H}^{\prime}$ below $\mathrm{H}^{\prime}=1.5$ is due to larger masses for the coil systems and for the blankets and shields $\left(\propto R_{0}^{2}\right)$. The helical and VF coil masses increase with decreasing $\mathrm{H}^{\prime}$ because of both the increasing coil lengths $\left(\propto R_{0}\right)$ and the increasing coil cross sections [area $\propto B_{0} R_{0} j$, where both $B_{0}$ and $K_{0}$ increase with decreasing $\mathrm{H}^{\prime}$ and $j$ decreases (from $50 \mathrm{MA} \cdot \mathrm{m}^{-2}$ at $\mathrm{H}^{\prime}=2.5$ to $18 \mathrm{MA} \cdot \mathrm{m}^{-2}$ at $\left.\mathrm{H}^{\prime}=1\right)$ ]. Figure 10 shows the impact on the cost of the FPC as the mass of its main components changes with $\mathrm{H}^{\prime}$. For reasonable values of $\mathrm{H}^{\prime}$ $(>1.5)$, the coils represent a relatively small fraction of the cost of the FPC.

These results indicate that only a modest improvement in confinement is needed for an attractive torsatron reactor. We choose $\mathrm{H}^{\prime}=2$ as a conservative target for stellarator confinement improvement. Better confinement improvement factors have been obtained in tokamaks (ARIES-I required $\mathrm{H}^{\prime}=2.5$ ). There is already some evidence for confinement improvement $(-30 \%)$ in stellarators due to either $\mathrm{H}$-mode-like operation or beta self-stabilization effects.

Possible confinement improvement techniques include control of the edge electric field, operation in the second stability regime, and field shaping to reduce the effective field ripple.

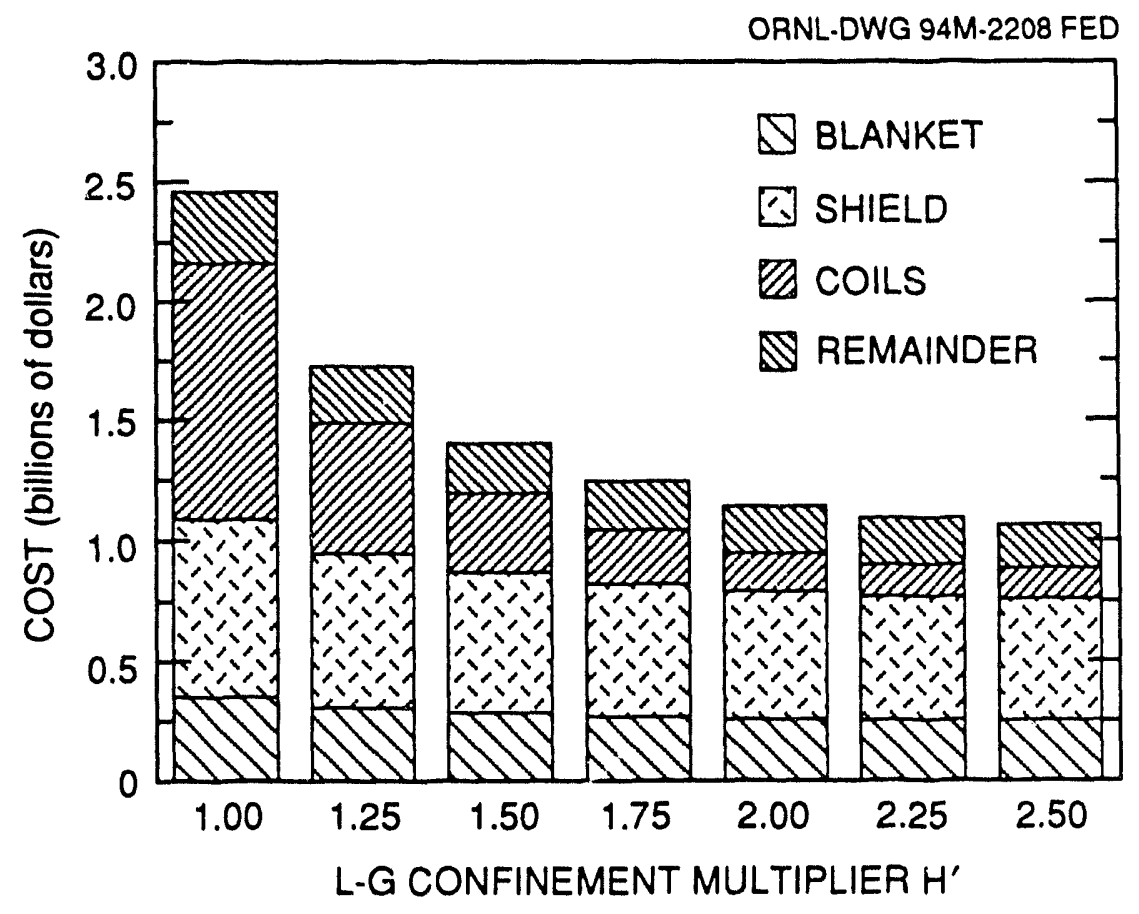

Fig. 10. Dependence of the cost of the fusion power core components on the LacknerGottardi confinement improvement factor $\mathrm{H}^{\prime}$. 


\section{EFFECTS OF OTHER ASSUMPTIONS}

The COE is relatively insensitive to the confinement improvement factor (and other parameter assumptions) because $R_{0}$ (and hence the cost of the FPC and the COE) can only be reduced by decreasing $A_{\Delta}$ (a different coil configuration), $d$ (a thinner blanket and shield), or $w$ (lower $B_{0}$, higher $j k$ ); $R_{0}=A_{\Delta}(d+w)$. Here $A_{\Delta}=6.37$ and $d=1.3 \mathrm{~m}$. For six field periods,

$$
w=0.456\left(B_{0} R_{0} / j k\right)^{1 / 2},
$$

where $j$ is in $\mathrm{MA} \cdot \mathrm{m}^{-2}$. For $k=3, j=50 \mathrm{MA} \cdot \mathrm{m}^{-2}$, and typical values for $B_{0}(5 \mathrm{~T})$ and $R_{0}$ $(10 \mathrm{~m}), w=0.26 \mathrm{~m}$, which is much less than the $d=1.3-\mathrm{m}$ thickness of the fixed components. The only way to reduce $R_{0}$ (and the $\mathrm{COE}$ ) is by reducing $B_{0}$, which reduces $\tau_{\mathrm{E}}$ and increases $\beta$, or by increasing $j$ and $k$, which are subject to other constraints. Combining eq. (5) with $R_{0}=A_{\Delta}(d+w)$ gives $R_{0} \approx A_{\Delta} d\left(1+0.456\left[A_{\Delta} B_{0} / j k d\right]^{1 / 2}\right)$.

\subsection{COIL ASSUMPTIONS}

A nominal set of coil parameters was chosen for the base reference case. The most critical parameters $\left(j, k\right.$, and $\left.B_{\max }\right)$ were varied over representative ranges to test the sensitivity of the reactor parameters to these choices. Increasing any of these decreases $w$ and hence $R_{0}\left(\Delta R_{0}=A_{\Delta} \Delta w\right)$ and the cost of the FPC of the reactor. Decreasing the current density from $50 \mathrm{MA} \cdot \mathrm{m}^{-2}$ to $30 \mathrm{MA} \cdot \mathrm{m}^{-2}$ increased $R_{0}$ from $10 \mathrm{~m}$ to $10.5 \mathrm{~m}$ and the COE from $65.6 \mathrm{mill} / \mathrm{kW}(\mathrm{e}) \mathrm{h}$ to $70.6 \mathrm{mill} / \mathrm{kW}(\mathrm{e}) \mathrm{h}$. The higher value for $j$ is allowed here because $B_{0}$ (and the hoop force) is lower than in the ARIES cases.

The COE is more sensitive to changes in the transverse coil elongation, as indicated in Table 7. As $k$ increases, $w$ decreases and hence $R_{0}$, the FPC mass, and the COE decrease. The

Table 7. Effect of transverse coil elongation $k$ on CT6 reactor parameters

\begin{tabular}{lccccc}
\hline & $k=1$ & $k=2$ & $k=3$ & $k=4.5$ & $k=12.9$ \\
\hline Density-averaged temperature $\langle T\rangle(\mathrm{keV})$ & 8.22 & 7.87 & 7.69 & 7.59 & 7.44 \\
Volume-averaged density $\langle n\rangle\left(10^{20} \mathrm{~m}^{-3}\right)$ & 0.91 & 1.15 & 1.30 & 1.39 & 1.55 \\
Volume-averaged beta $\langle\beta\rangle(\%)$ & 2.80 & 2.99 & 3.09 & 3.14 & 3.23 \\
Major radius $R_{0}(\mathrm{~m})$ & 12.27 & 10.72 & 10.03 & 9.64 & 9.07 \\
Toroidal field on axis $B_{0}(\mathrm{~T})$ & 4.55 & 4.85 & 5.01 & 5.11 & 5.26 \\
Coil current density $j\left(\mathrm{MA} \cdot \mathrm{m}^{-2}\right)$ & 29.6 & 37.0 & 46.4 & 50.0 & 50.0 \\
Radial depth of $\mathrm{HF}$ coil $2 w(\mathrm{~m})$ & 1.25 & 0.77 & 0.55 & 0.43 & 0.25 \\
Fraction of area under inboard HF & 0.17 & 0.20 & 0.22 & 0.24 & 0.33 \\
Separation between windings on the & 3.13 & 2.34 & 2.00 & 1.57 & 0 \\
$\quad$ inboard side (m) & & & & & \\
Separation between windings on the & 9.58 & 7.93 & 7.20 & 6.55 & 4.58 \\
$\quad$ outboard side (m) & & & & & \\
Fusion power core mass $\left(10^{3}\right.$ tonnes) & 14.47 & 10.66 & 8.87 & 8.12 & 7.31 \\
Cost of electricity [mill/kW $(\mathrm{e}) \mathrm{h}]^{(\mathrm{a})}$ & 81.0 & 70.4 & 65.6 & 63.4 & 60.4 \\
\hline
\end{tabular}

(a) In constant 1992 dollars. 
current density increases to compensate for the factor of 1.9 decrease in the cross-sectional area $\left(4 k w^{2}\right)$ of the $\mathrm{HF}$ windings as $k$ increases from 1 (a square cross section) to 12.9 (adjacent winding packs on the inboard side, as in a tokamak). The density increases by a factor of 1.7 because of the factor of 2.5 decrease in the plasma volume and the factor of 1.2 increase in $B_{0}$ [see eq. (4)]; there are smaller changes in $\langle\beta\rangle$ and $\langle T\rangle$. The COE is $81 \mathrm{mill} / \mathrm{kW}(\mathrm{e}) \mathrm{h}$ for $k=1$ (where $B_{\max }=16 \mathrm{~T}$ and $R_{0}=12.3 \mathrm{~m}$ ) and $60.4 \mathrm{mill} / \mathrm{kW}(\mathrm{e}) \mathrm{h}$ for $k=12.9$ (where $B_{\max }=10.1 \mathrm{~T}$ and $R_{0}=9.1 \mathrm{~m}$ ). We choose $k=3$ (vs 2.6 for ARIES-I) as a compromise; higher values of $k$ yield a smaller coil depth that leads to smaller values for $R_{0}$, $B_{\max }$, and the COE; lower values yield more room for blankets between the helical windings on the inboard side. The fraction of the surface area without a blanket (that under the inboard half of the $\mathrm{HF}$ winding pack and the associated shield) increases from $17 \%$ at $k=1$, which is acceptable, to $33 \%$ at $k=12.9$, which is not acceptable because it is also necessary to leave room for the divertor (which requires $5.5 \%$ of the wall area at $k=1$ and $9.9 \%$ at $k=12.9$ for an average $3 \mathrm{MW} \cdot \mathrm{m}^{-2}$ at the entrance to the divertor).

Lower values for $B_{\max }$ are possible with a somewhat increased $\mathrm{COE}$, as shown in fig. 11. The COE increases with decreasing $B_{\max }$ because $R_{0}$ increases from $10 \mathrm{~m}$ at $B_{\max }=$ $16 \mathrm{~T}$ to $12.8 \mathrm{~m}$ at $B_{\max }=8 \mathrm{~T}$. The value for $j$ has the largest variation (from $46.4 \mathrm{MA} \cdot \mathrm{m}^{-2}$ at $B_{\max }=16 \mathrm{~T}$ to $7.8 \mathrm{MA} \cdot \mathrm{m}^{-2}$ at $B_{\max }=8 \mathrm{~T}$ ) because the value of $B_{\max }$ depends on the perimeter of the helical winding cross section; lower $B_{\max }$ leads to a higher value for $w$ (and $R_{0}$ ) and hence to a lower $j$ for a given $B_{0}\left[j \propto 1 / w^{2}\right.$ from eq. (5)]. The values of the other parameters are relatively independent of the limiting value for $B_{\max } ; B_{0}$ and $\langle\beta\rangle$ change by $<11 \%$ as $B_{\max }$ varies from $8 \mathrm{~T}$ to $16 \mathrm{~T}$.

ORNL-DWG 94M-2212 FED

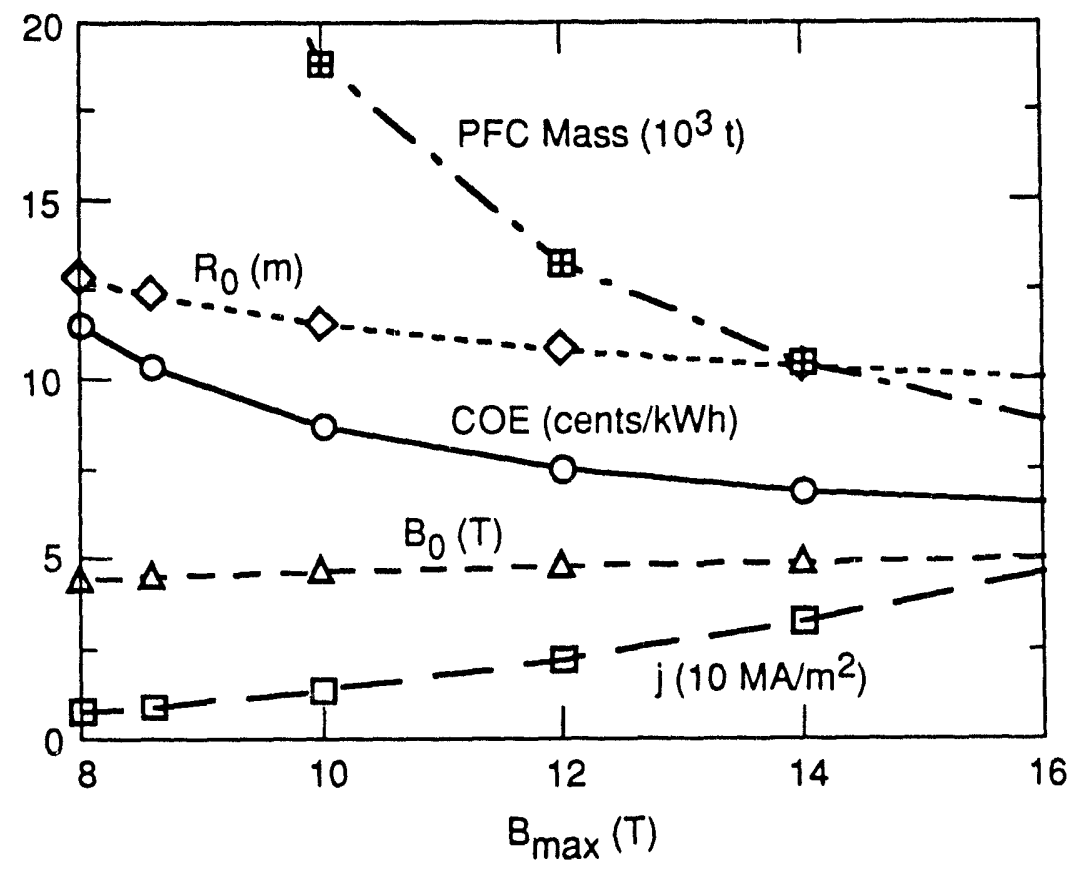

Fig. 11. Variation of reactor parameters with the maximum field on the superconducting winding pack. 
The reactor costs are relatively insensitive to any additional costs related to the geometrical complexity of the stellarator coils. Increasing the cost of the HF and VF coils by $25 \%$ increases the COE by $1.7 \%$. Increasing the cost of the blankets and the shields by $25 \%$ as well has a more dramatic effect, increasing the COE by $10.5 \%$.

\subsection{OTHER PARAMETER ASSUMPTIONS}

A nominal set of physics parameters was chosen for the base reference case. These parameters were then varied to test the sensitivity of the reactor parameters to these choices. The value of $\langle\beta\rangle$ obtained for the reference case is a modest $3.1 \%$. Values of $\langle\beta\rangle$ of $2 \%$ have already been obtained in experiments, and theory indicates that values more than twice this value should be attainable. If experiments were to indicate that this value was not attainable, then a slightly larger reactor size and higher COE would be required, as shown in fig. 12. For example, if operation were limited to $\langle\beta\rangle=2 \%$, then $R_{0}$ would be $5 \%$ larger and the COE would be $8.4 \%$ higher than the reference CT6 values. Even lowering the $\langle\beta\rangle$ limit to $1.5 \%$ would only increase $R_{0}$ by $9.1 \%$ and the COE by $17 \%$. Most of the variation in $\langle\beta\rangle$ is due to $B_{0}$; fig. 13 shows that $B_{0}{ }^{2}$ increases by a factor of 3 as $\langle\beta\rangle$ decreases from $3.1 \%$ to $0.7 \%$. The plasma volume increases (from $1400 \mathrm{~m}^{3}$ at $\langle\beta\rangle=3.1 \%$ to $2720 \mathrm{~m}^{3}$ at $\langle\beta\rangle=0.7 \%$ ), so $\langle T\rangle$ decreases to give the same output power; the plasma density is approximately constant. The value of $B_{\max }$ is constrained at $16 \mathrm{~T} ; w$ must increase (and hence $R_{0}$ and the $\mathrm{COE}$ ) as the required $\mathrm{HF}$ current increases to produce the increased $B_{0}$.

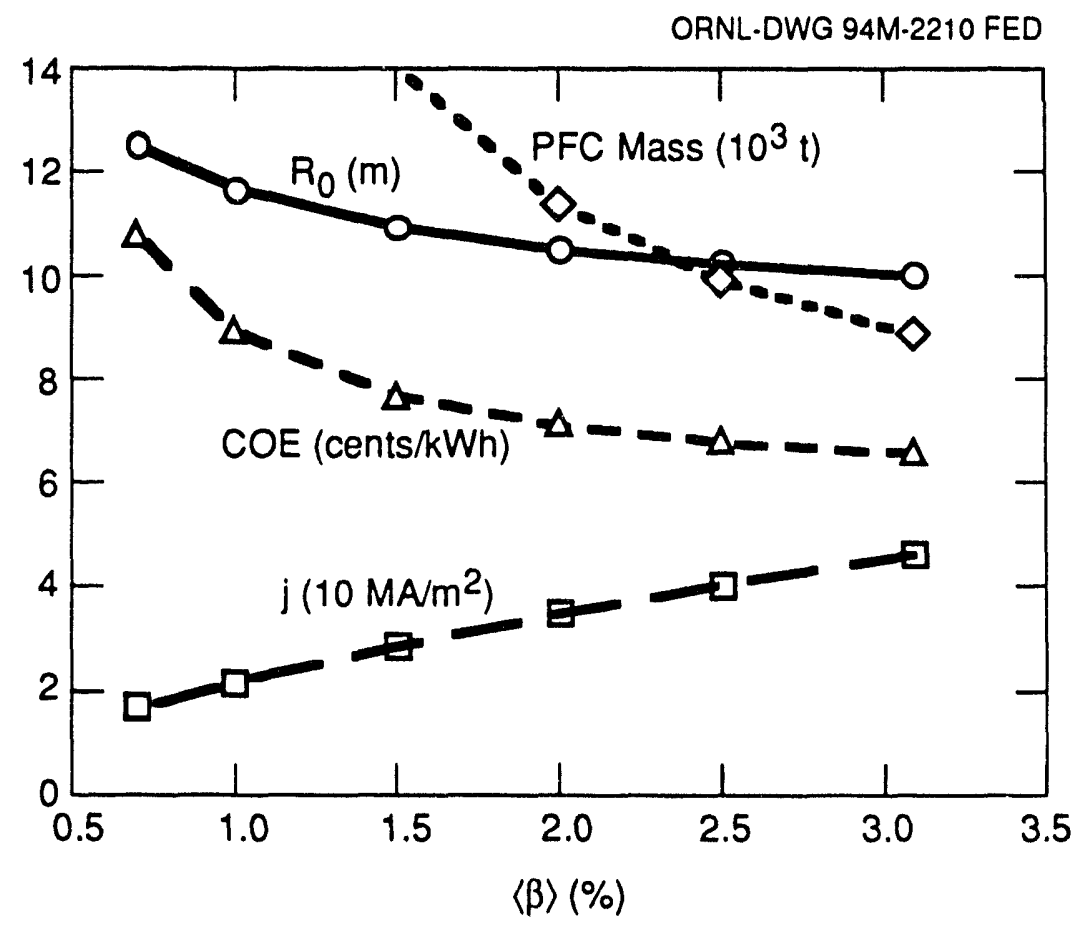

Fig. 12. Dependence of reactor parameters on the imposed beta limit. 


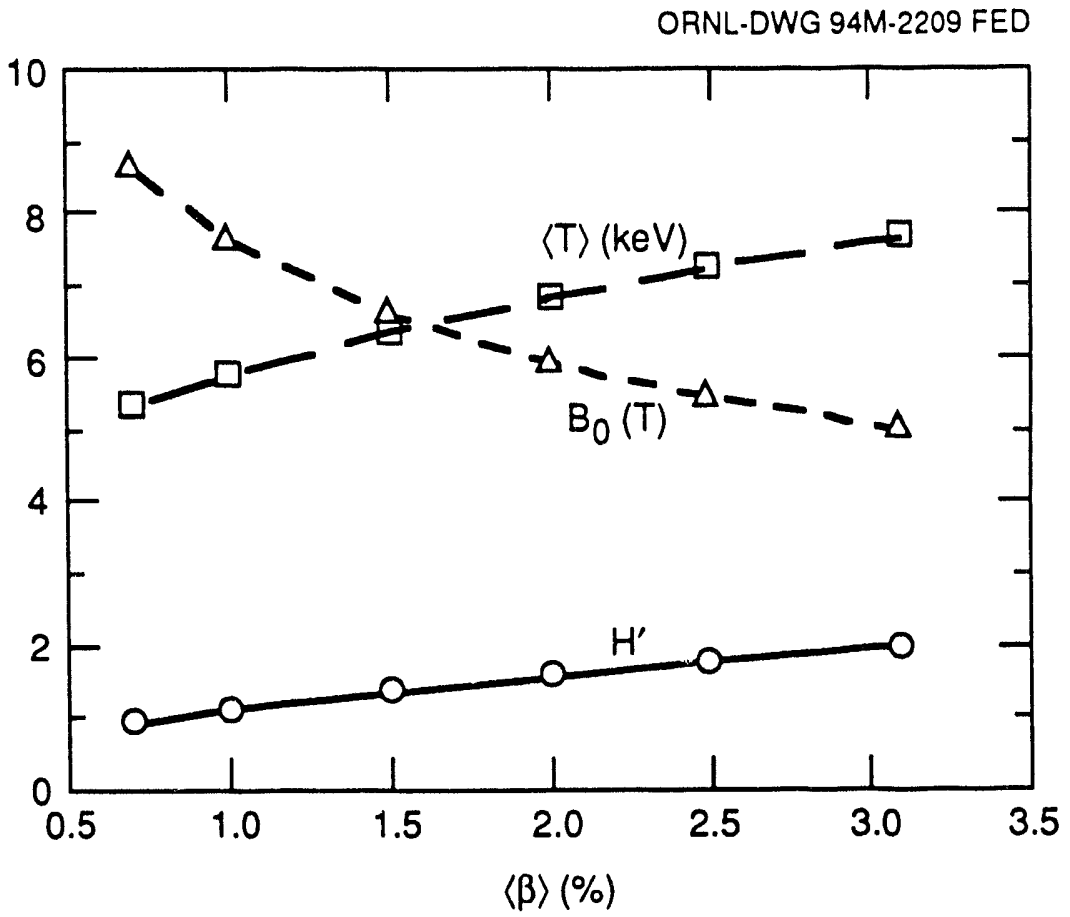

Fig. 13. Dependence of the plasma parameters on the imposed beta limit.

The correlation between $\langle\beta\rangle$ and $\mathrm{H}^{\prime}$ seen in fig. 13 is the same as that seen in fig. 8 where $\mathrm{H}^{\prime}$ was varied. These values are plotted in fig. 14. The optimum values (with respect to the minimum value for the $\mathrm{COE}$ ) for $\langle\beta\rangle$ and $\mathrm{H}^{\prime}$ are related and are not necessarily the limiting values. For constant $\langle T\rangle$ and $\mathrm{H}^{\prime},\langle\beta\rangle \propto\left(\mathrm{H}^{\prime}\right)^{2.5}$ because of the $P-0.6$ dependence in $\tau_{E}$ [16]. Here $\langle n\rangle$ is constant with $\mathrm{H}^{\prime}$ and $\langle\beta\rangle \propto\left(\mathrm{H}^{\prime}\right)^{2}$ because $\langle T\rangle$ (and the fraction of alphaparticle heating lost) changes with $\mathrm{H}^{\prime}$.

Other parameter variations have a smaller effect. Doubling the oxygen impurity fraction to $2 \%$ only increases the COE by $4.6 \%$. Removing the density limit [ 1.5 times the value given in eq. (4)] also has a modest effect; although $\langle n\rangle$ increases from $1.3 \times 10^{20} \mathrm{~m}^{-3}$ to $2.4 \times 10^{20} \mathrm{~m}^{-3}$ and $\langle T\rangle$ decreases from $7.7 \mathrm{keV}$ to $4 \mathrm{keV}$, the COE only decreases by $4 \%$.

\subsection{EFFECT OF ALPHA-PARTICLE LOSSES}

Modification of the magnetic configuration properties can significantly reduce the extent of the alpha-particle loss region, even to the point where the loss becomes negligible [3]. Eliminating the loss region reduces the fraction of alpha-particle power lost from $42 \%$ for the reference case to zero and increases the helium ash density from zero for the reference case to a density fraction that depends on the helium confinement time, which can be very long. The increasec' helium fraction leads to a smaller fuel ion fraction $n_{\mathrm{DT}} / n_{\mathrm{e}}$; the fusion power varies as $\left(n_{\mathrm{DT}} / n_{\mathrm{e}}\right)^{2}$ at a given ion temperature. Parameters for cases with assumed helium fractions of $5 \%$ [a $21 \%$ reduction in $\left(n_{\mathrm{DT}} / n_{\mathrm{e}}\right)^{2}$ ], $10 \%$ [a $39 \%$ reduction in $\left(n_{\mathrm{DT}} / n_{\mathrm{e}}\right)^{2}$ ], and $15 \%$ [a $55 \%$ reduction in $\left(n_{\mathrm{DT}} / n_{\mathrm{e}}\right)^{2}$ ] with no alpha-particle power loss are compared with 


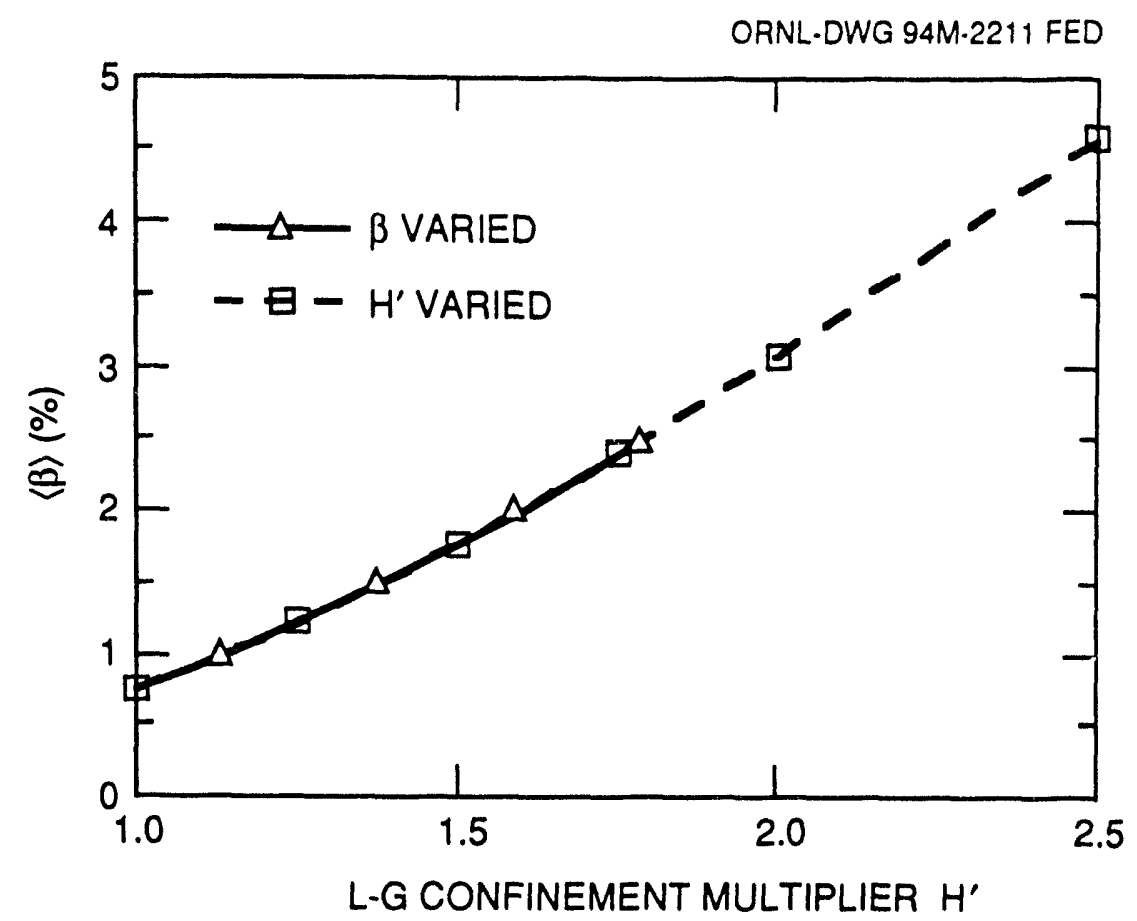

Fig. 14. Dependence of the optimum value for the volume-average $\beta$ on the LacknerGottardi confinement improvement factor $\mathrm{H}^{\prime}$.

those for the base case in Table 8; no solution could be found for a helium density fraction $>15 \%$. The plasma parameters for the base case adjust to compensate for the large alphaparticle power lost. Both $\langle n\rangle$ and $\langle T\rangle$ increase with helium content to keep the electrical power output at $1 \mathrm{GW}$; the total fusion power in charged particles is $354 \mathrm{MW}$ for all cases. The effect on the plasma power flow is shown in fig. 15. The conduction loss decreases with increasing helium fraction because the energy confinement time increases $(\langle n\rangle$ and the plasma volume increase). The radiation losses increase because both $\langle n\rangle$ and $\langle T\rangle$ increase with helium content. Despite the relatively large alpha-particle loss in the base case, the COE is only $3 \%$ more than that for the nominal $10 \%$ helium case with no alpha-particle power lost.

\subsection{OTHER COIL CONFIGURATIONS}

Two other coil configurations were studied to determine the sensitivity of the COE to the coil parameters: a nine-field-period Compact Torsatron (CT9) and a twelve-field-period Compact Torsatron (CT12) based on the ATF coil set [17]. The relevant coil parameters are $A_{\mathrm{p}}=3.77, A_{\mathrm{c}}=2.50$, and $A_{\Delta}=6.37$ for CT6; $A_{\mathrm{p}}=4.66, A_{\mathrm{c}}=3.24$, and $A_{\Delta}=8.60$ for CT9; and $A_{\mathrm{p}}=7.78, A_{\mathrm{c}}=4.49$, and $A_{\Delta}=9.50$ for CT12. For the same assumptions as for the reference CT6 case, the COE for CT12 is $66.8 \mathrm{mill} / \mathrm{kW}(\mathrm{e}) \mathrm{h}$. Although $R_{0}$ is $44 \%$ larger, the COE is only $1.8 \%$ higher than for the reference CT6 case because the area of the plasma surface from which the blanket and shield volumes are scaled is $4.6 \%$ less than for the CT6 case (due to the much lower value for $A_{\mathrm{p}}$ ). For CT9, the COE is $72.3 \mathrm{mill} / \mathrm{kW}(\mathrm{e}) \mathrm{h}, 10.2 \%$ higher than 
Table 8. Effect of alpha-particle losses and helium fraction on CT6 reactor parameters

\begin{tabular}{lcccc}
\hline & Base case & $\begin{array}{c}5 \% \\
\text { Helium }\end{array}$ & $\begin{array}{c}10 \% \\
\text { Helium }\end{array}$ & $\begin{array}{c}15 \% \\
\text { Helium }\end{array}$ \\
\hline Volume-averaged density $\langle n\rangle\left(10^{20} \mathrm{~m}^{-3}\right)$ & 1.30 & 1.56 & 1.64 & 1.70 \\
Density-averaged temperature $\langle T\rangle(\mathrm{keV})$ & 7.69 & 7.32 & 7.86 & 8.76 \\
Volume-averaged beta $\langle\beta\rangle(\%)$ & 3.09 & 5.14 & 5 & 4.62 \\
Major radius $R_{0}(\mathrm{~m})$ & 10.03 & 9.78 & 9.83 & 9.92 \\
Toroidal field on axis $B_{0}(\mathrm{~T})$ & 5.00 & 4.10 & 4.36 & 4.80 \\
Cost of electricity $[\mathrm{mill} / \mathrm{kW}(\mathrm{e}) \mathrm{h}]^{(\mathrm{a})}$ & 65.6 & 63.3 & 63.7 & 64.6 \\
\hline
\end{tabular}

(a) In constant 1992 dollars.

ORN. JG 94M-2213 FED

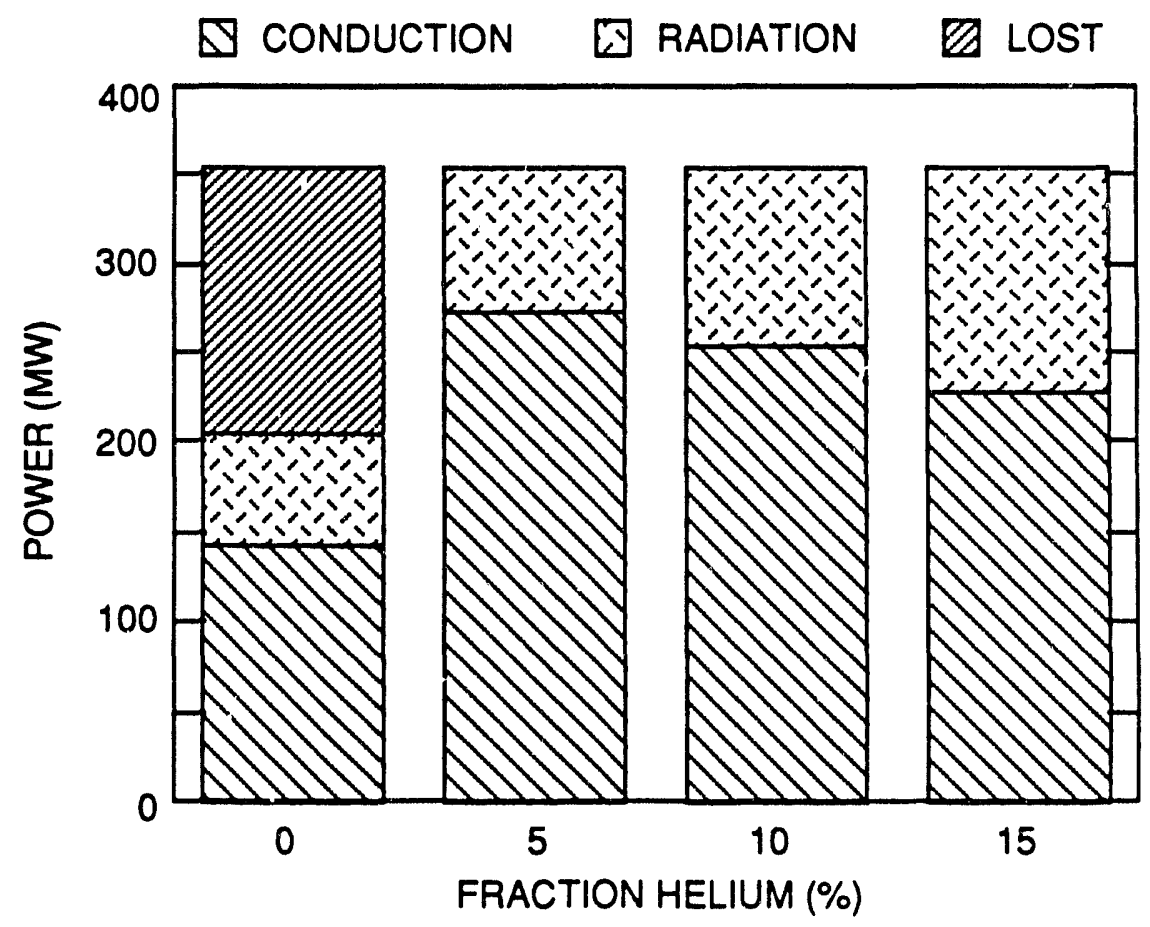

Fig. 15. Variation of the plasma power flow with helium fraction.

for the reference CT6 case. Although the value of $A_{\mathrm{p}}$ is larger than that for CT6, it is not large enough to compensate for the $32 \%$ larger value of $R_{0}$; the plasma surface area is $35 \%$ larger than that for the CT6 reference case.

Figure 16 shows the range of COE values obtained for CT6, CT9, CT12, and other torsatrons with different values of $A_{\mathrm{p}}$ (varying from 3.6 to 11.7) and $A_{\Delta}$ (varying from 6.4 to 


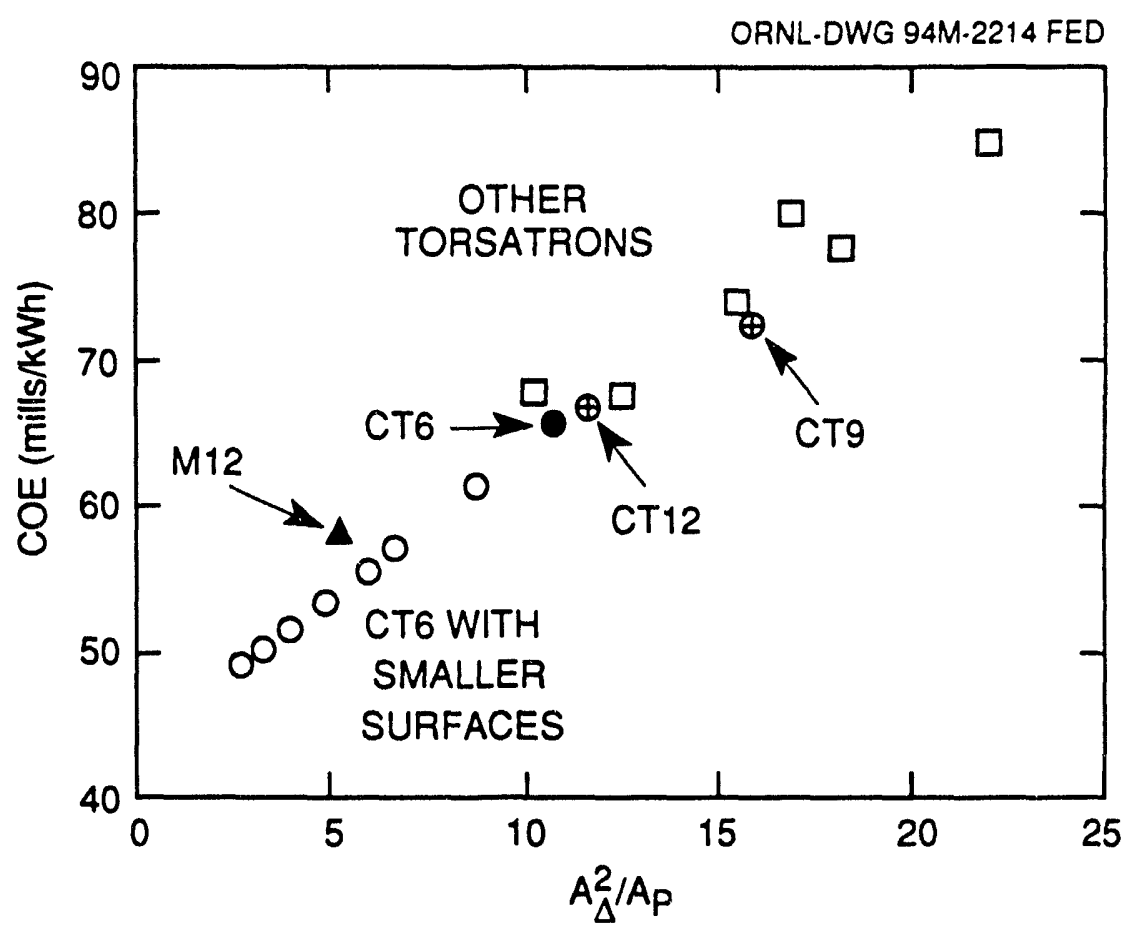

Fig. 16. Dependence of the cost of electricity on a parameter characterizing the relative wall surface area.

11.3). The COE depends on the parameter $A_{\Delta}^{2} / A_{\mathrm{p}}$, which characterizes the relative wall area, rather than on $A_{\Delta}$ or $A_{\mathrm{p}}$ separately because the most expensive components of the FPC are usually the blankets and shields, as indicated in fig. 10. For a given thickness, their cost $\propto$ wall area $\propto R_{0} a_{\mathrm{p}} \propto R_{0}{ }^{2} / A_{\mathrm{p}} \propto A_{\Delta}{ }^{2} / A_{\mathrm{p}}$.

Alternate coil configurations could lead to significantly lower values for the $C O E$. Figure 16 shows the reduction that could be obtained if the CT6 plasma-coil separation ratio $A_{\Delta}$ could be reduced for a fixed coil aspect ratio $A_{c}$. This is done in this calculation by placing the edge of the plasma at each of the successively smaller flux surfaces shown in fig. 2 , so that $A_{\mathrm{p}}$ increases as $A_{\Delta}$ decreases. However, in demonstrating the potential gain by reducing $A_{\Delta}$, this calculation avoids the issue of the diverted flux layer outside the last closed flux surface, which would have to be addressed. Recently, a twelve-field-period torsatron with $A_{\Delta}=7.25$ and $A_{\mathrm{p}}=9.97$ has been found (M12) that has the potential for much better performance than CT6, as well as having the strong advantage of one modular coil per field period [18]. The COE for this coil configuration is also shown in fig. 16.

\subsection{SCALING WITH ELECTRIC POWER OUTPUT}

All reactor cases studied thus far have a net electric power output $P_{\mathrm{E}}=1 \mathrm{GW}(\mathrm{e})$. Figure 17 shows the variation of the reactor parameters as $P_{E}$ is increased from $0.6 \mathrm{GW}(\mathrm{e})$ to $2 \mathrm{GW}(\mathrm{e})$ for the reference CT6 case. Although power plants with $P_{\mathrm{E}}<1 \mathrm{GW}(\mathrm{e})$ are possible, 


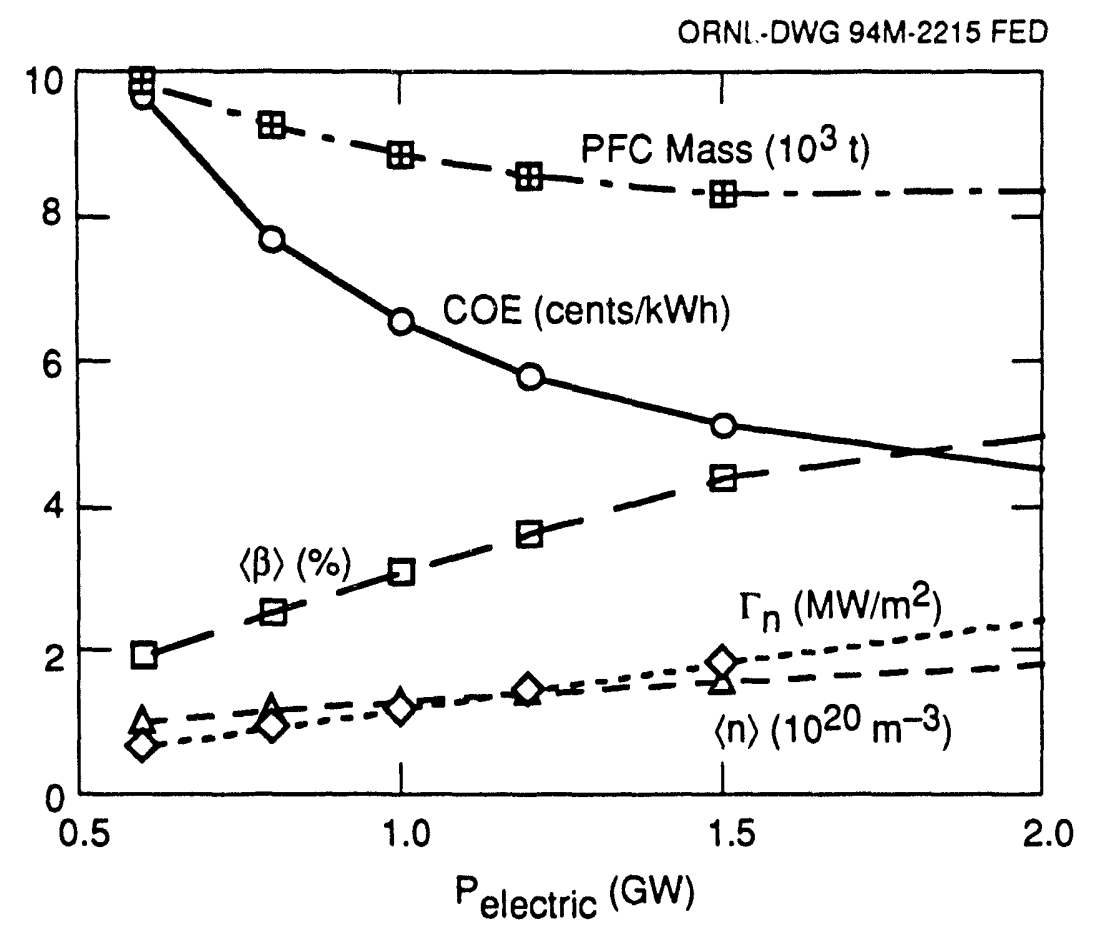

Fig. 17. Dependence of the cost of electricity and other reactor parameters on the net electric power output.

significant improvements in reactor economics can be obtained for larger power plants. Increasing the electric power output from $1 \mathrm{GW}(\mathrm{e})$ to $1.5 \mathrm{GW}(\mathrm{e})$ and $2 \mathrm{GW}(\mathrm{e})$ would reduce the COE by $22 \%$ and $31 \%$, respectively, if the costs of the reactor plant components continue to scale with power as they do at the $1-\mathrm{GW}(\mathrm{e})$ level and if the plant availability remains $76 \%$ at the higher powers. Even the relatively modest increase in $P_{\mathrm{E}}$ from $1 \mathrm{GW}(\mathrm{e})$ to $1.2 \mathrm{GW}(\mathrm{e})$ would reduce the COE by $11 \%$. The mass of the FPC (and its cost) is approximately independent of $P_{\mathrm{E}}$ because the reactor size does not change with $P_{\mathrm{E}} ; R_{0}$ is $10.2 \mathrm{~m}$ for $P_{\mathrm{E}}=$ $0.6 \mathrm{GW}(\mathrm{e})$ and $9.9 \mathrm{~m}$ for $P_{\mathrm{E}}=2 \mathrm{GW}(\mathrm{e})$. Essentially all the decrease in the COE with increasing $P_{\mathrm{E}}$ is due to the fact that the $\mathrm{COE}$ is inversely proportional to $P_{\mathrm{E}}$. The additional power results from an increase in $\langle n\rangle$ [from $1.0 \times 10^{20} \mathrm{~m}^{-3}$ for $P_{\mathrm{E}}=0.6 \mathrm{GW}(\mathrm{e})$ to $1.8 \times 10^{20} \mathrm{~m}^{-3}$ for $P_{\mathrm{E}}=2 \mathrm{GW}(\mathrm{e})$ ] and in $\langle T\rangle$ [from $7.3 \mathrm{keV}$ for $P_{\mathrm{E}}=0.6 \mathrm{GW}(\mathrm{e})$ to $8 \mathrm{keV}$ for $P_{\mathrm{E}}=2 \mathrm{GW}(\mathrm{e})$ ]. This leads to the nearly linear increase in $\langle\beta\rangle$ with $P_{\mathrm{E}}$ seen in fig. $17 ; B_{0}$ only decreases by $13 \%$ over this range. For constant $\langle T\rangle,\langle\beta\rangle \propto P_{\mathrm{E}}[16]$. Here $\langle\beta\rangle \propto P_{\mathrm{E}} 0.9$ because $\langle T\rangle$ and $\mathrm{H}^{\prime}$ change with $P_{\mathrm{E}}$.

\subsection{MORE CONSERVATIVE ASSUMPTIONS FOR THE BLANKET AND SHIELD}

The effect of a more conservative model for the shield can be studied by using the ARIES-IV model. The reactors studied in this paper employed blanket and shield models developed in the PULSAR study to reduce the total thickness of the blanket and shield under 
the inboard half of the helical windings, and thereby the size of the reactor. However, the PULSAR study uses the same blanket and shield models developed in the ARIES-IV study to allow a better comparison with ARIES-IV. If we use the ARIES-IV model, the thickness of the shield under the inboard half of the helical windings increases from $1 \mathrm{~m}$ to $1.15 \mathrm{~m}$, and the material changes from $\mathrm{SiC} / \mathrm{TiH}_{1.8} / \mathrm{Pb}$ to $\mathrm{SiC} / \mathrm{B}_{4} \mathrm{C}$. The thickness of the shield elsewhere increases from $0.75 \mathrm{~m}$ to $0.9 \mathrm{~m}$, and the material changes from $\mathrm{SiC}$ to $\mathrm{SiC} / \mathrm{B}_{4} \mathrm{C}$. The blankets are unchanged. The net effect is to increase the COE for the reference case by $11 \%$ to $72.6 \mathrm{mill} / \mathrm{kW}(\mathrm{e}) \mathrm{h}$.

It may be necessary to have a blanket under the inboard half of the helical windings to obtain the required tritium breeding ratio. In that case, we assume a blanket thickness of $0.5 \mathrm{~m}$ and a shield thickness of $0.85 \mathrm{~m}$ everywhere around the plasma. The minimum distance from the plasma edge to the face of the HF winding pack is then $1.6 \mathrm{~m}$ vs $1.3 \mathrm{~m}$ for the reference assumption. However, it is no longer necessary in this case to leave space between the HF windings on the inboard side for the blanket, and the transverse elongation of the windings can be increased until they touch on the inboard side $(k=18)$, as in a tokamak. The resulting COE is 67.6 mill $/ \mathrm{kW}(\mathrm{e}) \mathrm{h}$, only $3 \%$ higher than that for the base case. Although this case has larger values for $R_{0}(11.2 \mathrm{~m})$ and FPC mass $(9,850$ tonnes) than the reference CT6 case, it has two significant advantages over the CT6 case: only $7 \%$ of the wall area is not covered by a blanket (vs $30 \%$ for CT6) and the maximum field on the superconducting winding pack is only $9.1 \mathrm{~T}$ (vs $16 \mathrm{~T}$ for CT6), which allows the use of NbTi rather than $\mathrm{Nb}_{3} \mathrm{Sn}$ as the superconductor.

\subsection{EFFECT OF MODULARIZATION}

The cases discussed thus far (except for M12) are based on continuous helical windings. Although used in this scoping study for simplicity in calculations and comparisons, continuous helical windings may not be practical in a reactor in which it may be necessary to replace a coil, even if the coils are not as stressed as those in a tokamak reactor. As discussed in Sect. 2.1, helical windings may be modularized in the symmotron fashion [7] or with several nonplanar TF coils per field period [8]. The symmotron option is simulated in our calculations by adding (1) VF coil segments that connect the beginning and end of each field period and carry the full helical coil current, and (2) extra VF coils to give the correct net VF coil currents. This approach is inefficient because it requires additional coil mass, but it does preserve the open space between the helical windings for blankets and maintenance, which leads to smaller- $R_{0}$ reactors. The resulting $C O E$ is $<1 \%$ higher than that for the reference CT6 case. The M12 modularization is similar, but the windbacks are located at larger radius and thus avoid the sharp coil bends that characterize the symmotron.

Modularization using nonplanar TF coils [8] is simulated by reducing the effective helical extent of the coils by a factor of 2 and eliminating the VF coils. The modular TF coil set produces the magnetic configuration more efficiently than a helical coil system that requires a VF coil with current in the direction opposite to that in the helical coils. However, this type of modularization results in coils that are closer to the plasma (larger $A_{\Delta}$ ) and, hence, a larger value for $R_{0}$. There is no longer enough space between the nonplanar TF coils on the inboard half of the torus for the blanket segments, so a blanket must be used everywhere on the inboard side. A CT6 reactor of this type would have a significantly larger COE. 


\section{CONCLUSIONS AND DISCUSSION}

Stella rators have significant operational advantages over tokamaks as ignited steadystate reactors. This scoping study shows that a torsatron reactor could also be competitive with a tokamak reactor for a range of assumptions. The COE for the 1-GW(e) CT6 reference case, $65.6 \mathrm{mill} / \mathrm{kW}(\mathrm{e}) \mathrm{h}$ in constant 1992 dollars, allows relaxing different assumptions and constraints while still keeping the COE competitive. The COE is relatively insensitive $(<10 \%$ variation) over a wide range of assumptions, including variations in $B_{\max }$, the coil elongation, the shape of the density profile, the beta limit, the confinement multiplier, and the presence of a large loss region for alpha particles. The optimum values for $\langle\beta\rangle$ and $\mathrm{H}^{\prime}$ are related and are not necessarily the limiting values; moderate values are sufficient for a competitive $\mathrm{COE}$ : $\langle\beta\rangle \geq 2 \%$ and $H^{\prime} \geq 1.5$. The value of $B_{\max }$ on the winding pack can also be relaxed; a competitive $C O E$ is obtained for $B_{\max } \geq 10 \mathrm{~T}$. The largest variations in the COE occur for variations in the electrical power output demanded and the plasma-coil separation ratio. The COE is not affected by the relatively large alpha-particle losses assumed here.

The CT6 torsatron configuration examined in this paper is not an "optimum" stellarator configuration for the reactor application; it is only one of the family of Compact Torsatron configurations [6] that were obtained by maximizing the average radius of the last closed magnetic surface, subject to MHD constraints that maximized the $\langle\beta\rangle$ limit. While this is desirable for an experiment, it tends to minimize the critical distance $\Delta$ between the plasma edge and the center of the coil winding pack, rather than maximizing it as needed for the reactor application. The COE could be reduced significantly if the ratio $A_{\Delta}{ }^{2} / A_{\mathrm{p}}$ could be decreased, as shown in fig. 16.

Although results to date are encouraging, further work on optimization of the coil configuration is needed in a number of areas to define an improved reference case: (1) improved low-aspect-ratio torsatron configurations with feasible modular coils that preserve the open helical structure of torsatrons and allow more room between the plasma edge and the center of the coils, which would reduce the size (and cost) of the reactor, such as M12; (2) 3-D neutronics calculations to determine the required thickness of the side shields for the inboard coils, which determines the maximum allowable elongation for the coils and hence their minimum radial depth; (3) shaping of the coil cross section, as is done in ATF and LHD, to allow more room at the sides of the coil for neutron shielding; (4) 3-D calculation of the maximum field on modular coils, which determines the maximum current density and stress in these coils; (5) optimization of the divertor geometry and its impact on the blanket design; and (6) 3-D calculations of the beta limits and ripple-induced transport for modular coil stellarators with optimized magnetic configurations and optimized plasma profiles. The emphasis on finding a modular-coil version of the torsatron is due to concerns about fabrication and repair of large helical windings. Also, more may be gained by looking at other stellarator reactor candidates.

As stellarators approach the reactor collisionality regime, ripple-induced losses of thermal particles and compensating electric field effects should become more important. The simple 1-D transport model used in this paper for comparison with the ARIES tokamak reactor studies can be replaced with a more refined 1-D ripple-induced stellarator transport model 
[19]. Calculations of this type have been done for a torsatron reactor configuration with fixed parameters: $R_{0}=10 \mathrm{~m}, A_{\mathrm{p}}=5$, and $B_{0}=5 \mathrm{~T}[20]$.

To see the effect of the neoclassical ripple-induced losses on stellarator reactor optimization, the CT6 case was calculated using the Shaing-Houlberg 1-D ripple-induced stellarator transport model [19]. The assumptions were the same as for the CT6 reference case except that the thermal diffusivity based on Lackner-Gottardi scaling was replaced by the ripple-induced diffusivities and an anomalous electron thermal conductivity, and the offdiagonal ( $\nabla n$ and $\nabla \phi$ terms) were included in the 1-D electron and ion heat flow equations. The electric potential $\phi$ was assumed to be parabolic with $\phi(0)=\xi_{0} T_{i}(0)$. Two cases were studied: an "ion-root" case with $\xi_{0}=-2.5\left(\xi_{0}=-2.3\right.$ was obtained for self-consistent ambipolar neoclassical transport in ref. [21]) and an "electron-root" case with $\xi_{0}=+3.5$. The projected COE for the two cases was $64.4 \mathrm{mill} / \mathrm{kW}(\mathrm{e}) \mathrm{h}$ and $64.9 \mathrm{mill} / \mathrm{kW}(\mathrm{e}) \mathrm{h}$, respectively, not very different from the $65.6 \mathrm{mill} / \mathrm{kW}(\mathrm{e}) \mathrm{h}$ found for the reference CT6 case. The next step would be to incorporate the self-consistent 1-D calculation [21] of the radial profiles of the ion and electron temperatures and densities and the ambipolar radial electric field into the optimization.

Further improvement in the outlook for torsatron reactors, and for stellarator reactors in general, depends on establishing the physics basis needed for reactor extrapolation and on further optimizing the stellarator coil configuration. Present stellarators [2] can develop much of the physics basis needed for stellarator optimization. ATF was designed to study beta optimization and confinement improvement through access to the second-stability regime. Wendelstein 7-AS was designed to study confinement improvement through reduction of the Pfirsch-Schlüter current. The Compact Helical System was designed to study stellarator behavior at lower aspect ratio. DIII-D-scale stellarators with superconducting coils that can demonstrate true steady-state operation, effective control of particles and impurities with divertors, and significantly higher plasma parameters $\left(\beta, T_{\mathrm{i}}, n \tau_{E} T_{\mathrm{i}}\right)$ are now under construction in Japan (LHD) and in the design and approval phase in Germany (Wendelstein 7-X). 


\section{REFERENCES}

[1] B. A. Carreras, G. Grieger, J. H.Harris, J. L. Johnson, J. F. Lyon, et al., Progress in stellarator/heliotron research: 1981-1986, Nucl. Fusion 28 (1988) 1613.

[2] J. F. Lyon, Near-term directions in the world stellarator program, Fusion Technol. 17 (1990) 19.

[3] S. L. Painter and J. F. Lyon, Alpha-particle losses in Compact Torsatron Reactors, Fusion Technol. 16 (1989) 157.

[4] R. W. Conn and F. Najmabadi, Visions of the future, a program in tokamak reactor studies, UCLA-PPG-1201, University of California, Los Angeles (1987); also R. L. Miller, R. A. Krakowski, and the ARIES TEAM, Options and optimizations for tokamak reactors: ARIES, Fusion Technol. 19 (1991) 802.

[5] F. Najmabadi, R. W. Conn, and the ARIES team, The ARIES-I tokamak reactor study, UCLA-PPG-1323, University of California, Los Angeles (1992).

[6] B. A. Carreras, N. Dominguez, L. Garcia, et al., Low-aspect-ratio torsatron configurations, Nucl. Fusion 28 (1988) 1195.

[7] J. F. Lyon, B. A. Carreras, J. H. Harris, et al., Stellarator physics evaluation studies, Proc. 9th Int. Conf. Plasma Physics and Controlled Nuclear Fusion Research, Baltimore, Maryland, 1982, Vol. 3, p. 115, International Atomic Energy Agency, Vienna (1983).

[8] G. Grieger, E. Harmeyer, W. Lotz, et al., Modular stellarator reactors and plans for Wendelstein 7-X, Fusion Technol. (1992) 21, 1767.

[9] The ARIES team, The ARIES-II and ARIES-IV Tokamak reactor study, UCLA-PPG1461, University of California, Los Angeles (to be published).

[10] PULSAR Group, private communication, 1993.

[11] S. Sudo, Y. Takeiri, H. Zushi, et al., Scalings of energy confinement and density limit in stellarator/heliotron devices, Nucl. Fusion 30 (1990) 11.

[12] R. J. Goldston, H. Biglari, G. W. Hammett, et al., $\tilde{E} \times B / B^{2}$ vs $v_{\|} \mathbb{B} / B$ as the cause of transport in tokamaks, Bull. Am. Phys. Soc. 34 (1989) 1964.

[13] K. Lackner and N. A. O. Gottardi, Tokamak confinement in relation to plateau scaling, Nucl. Fusion 30 (1990) 767.

[14] J. P. Holdren et al., Report of the Senior Committee on enviromental, safety, and economic aspects of magnetic fusion energy, Lawrence Livermore National Laboratory Report UCRL-53766 (1989); also J. G. Delene, Updated comparison of economics of fusion reactors with advanced fission reactors, Fusion Technol. 19 (1991) 807.

[15] The ARIES Team, Lessons learned from the tokamak advanced reactor innovation and evaluation study (ARIES), (in preparation).

[16] J. F. Lyon and S. L. Painter, Assessment of torsatrons as reactors, ORNL/TM-12189, Oak Ridge National Laboratory (1992).

[17] J. F. Lyon, B. A. Carreras, K. K. Chipley, et al., "The Advanced Toroidal Facility," Fusion Technol. 10 (1986) 179.

[18] J. A. Rome, private communication (1994).

[19] D. E. Hastings, W. A. Houlberg and K. C. Shaing, The ambipolar electric field in stellarators, Nucl. Fusion 25 (1985) 445. 
[20] S. L. Painter and J. F. Lyon, Transport analysis of stellarator reactors, Nucl. Fusion 31 (1991) 2271.

[21] S. L. Painter and P. N. Stevens, Design-oriented methods for one-dimensional analysis of fusion reactor plasma performance, Fusion Technol. 21 (1992) 1617. 
ORNL/TM- 12670

Dist. Category UC-420

\section{INTERNAL DISTRIBUTION}

1. Director, Fusion Energy Division

2. C. C. Baker

3. D. B. Batchelor

4. L. A. Berry

5. B. A. Carreras

6. R. J. Colchin

7. R. A. Dory

8. M. S. Lubell

9. T. E. Shannon

10. W. L. Stirling

11. R. P. Leinius

12-13. Laboratory Records Department

14. Laboratory Records, ORNL-RC

15-16. Central Research Library

17. Document Reference Section
18. Fusion Energy Division Library

19-20. Engineering Technology/Fusion Energy Division Fublications Office

21. ORNL Patent Office

22-61. J. F. Lyon

62. W. Fulkerson

63. J. H. Harris

64. S. P. Hirshman

65. W. A. Houlberg

66. P. K. Mioduszewski

67. M. Murakami

68. Y-K. M. Peng

69. J. A. Rome

70. N. A. Uckan

\section{EXTERNAL DISTRIBUTION}

71. S. M. Hamberger, Research School of Physical Sciences, Australian National University, P.O. Box 4, Canberra, A.C.T. 2601, Australia

72. Office of the Asssistant Manager for Energy Research and Development, U.S. Department of Energy, Oak Ridge Operations, P.O. Box 2000; Oak Ridge, TN 37831

73. N. A. Davies, Director, Office of Fusion Energy, Office of Energy Research, ER-50 Germantown, U.S. Department of Energy, Washington, DC 20545

74. M. Roberts, International Programs, Office of Fusion Energy, Office of Energy Research, ER-52 Germantown, U.S. Department of Energy, Washington, DC 20545

75. D. E. Baldwin, Lawrence Livermore National Laboratory, P.O. Box 5511, Livermore, CA 94550

76. R. W. Conn, Mechanical, Aerospace, and Nuclear Engineering Department, 6291 Boelter Hall, University of California, Los Angeles, CA 90024-1597

77. P. C. Liewer, MS 138-208, Jet Propulsion Laboratory, 4800 Oak Grove Drive, Pasadena, CA 91109

78. R. Parker, Plasma Fusion Center, Massachusetts Institute of Technology, 167 Albany St., NW16-288, Cambridge, MA 02139

79. K. I. Thomassen, L-637, Lawrence Livermore National Laboratory, P.O. Box 5511, Livermore, CA 94550 
80. J. D. Callen, Department of Nuclear Engineering, University of Wisconsin, Madison, WI 53706-1687

81. S. O. Dean, Fusion Power Associates, Inc., 2 Professional Drive, Suite 248, Gaithersburg, MD 20879

82. H. K. Forsen, Bechtel Group, Inc., Research Engineering, P.O. Box 3965, San Francisco, CA 94119

83. R. W. Gould, Department of Applied Physics, California Institute of Technology, Pasadena, CA 91125

84. R. A. Gross, Plasma Research Laboratory, Columbia University, New York, NY 10027

85. R. J. Hawryluk, Princeton Plasma Physics Laboratory, P.O. Box 451, Princeton, NJ 08543

86. D. M. Meade, Princeton Plasma Physics Laboratory, P.O. Box 451, Princeton, NJ 08543

87. W. M. Stacey, School of Nuclear Engineering and Health Physics, Georgia Institute of Technology, Atlanta, GA 30332

88. D. Steiner, Nuclear Engineering Department, NES Building, Tibbetts Avenue, Rensselaer Polytechnic Institute, Troy, NY 12181

89. R. Varrna, Physical Research Laboratory, Navrangpura, Ahmedabad 380009, India

90. Bibliothek, Max-Planck I.stitut fur Plasmaphysik, Boltzmannstrasse 2, D-8046 Garching, Federal Republic of Germany

91. Bibliothek, Institut für Plasmaphysik, KFA Jülich GmbH, Postfach 1913, D-5170 Jülich, Federal Republic of Germany

92. Bibliothek, KfK Karlsruhe GmbH, Postfach 3640, D-7500 Karlsruhe 1, Federal Republic of Germany

93. Bibliotheque, Centre de Recherches en Physique des Plasmas, Ecole Polytechnique Federale de Lausanne, 21 Avenue des Bains, $\mathrm{CH}-1007$ Lausanne, Switzerland

94. R. Aymar, CEN/Cadarache, Departement de Recherches sur la Fusion Contrôlée, F-13108 Saint-Paul-lez-Durance Cedex, France

95. Bibliotheque, CEN/Cadarache, F-13108 Saint-Paul-lez-Durance Cedex, France

96. Library, JET Joint Undertaking, Abingdon, Oxfordshire OX14 3EA, England

97. Library, FOM-Instituut voor Plasmafysica, Rijnhuizen, Edisonbaan 14, $3439 \mathrm{MN}$ Nieuwegein, The Netherlands

98. Library, National Institute for Fusion Science, Chikusa-ku, Nagoya 464-01, Japan

99. Library, International Centre for Theoretical Physics, P.O. Box 586, I-34100 Trieste, Italy

100. Library, Centro Ricerche Energia Frascati, C.P. 65, I-00044 Frascati (Roma), Italy

101. Library, Plasma Physics Laboratory, Kyoto University, Gokasho, Uji, Kyoto 611, Japan

102. Plasma Research Laboratory, Australian National University, P.O. Box 4, Canberra, A.C.T. 2601, Australia

103. Library, Japan Atomic Energy Research Institute, Naka Fusion Research Establishment, 801-1 Mukoyama, Naka-machi, Naka-gun, Ibaraki-ken, Japan 
104. G. A. Eliseev, I. V. Kurchatov Institute of Atomic Energy, P.O. Box 3402, 123182 Moscow, Russia

105. V. A. Glukhikh, Scientific-Research Institute of Electro-Physical Apparatus, 188631 St. Petersburg, Russia

106. I. Shpigel, Institute of General Physics, Academy of Sciences, Ulitsa Vavilova 38, Moscow, Russia

107. D. D. Ryutov, Institute of Nuclear Physics, Siberian Branch of the Academy of Sciences Sovetskaya St. 5, 630090 Novosibirsk, Russia

108. 0. Pavlichenku, Kharkov Physical-Technical Institute, Academical St. 1, 310108 Kharkov, Ukraine

109. Deputy Director, Southwestern Institute of Physics, P.O. Box 15, Leshan, Sichuan, China (PRC)

110. Director, The Institute of Plasma Physics, P.O. Box 1126, Hefei, Anhui, China (PRC)

111. R. A. Blanken, Experimental Plasma Physics Research Branch, Division of Applied Plasma Physics, Office of Energy Research, ER-542, Germantown, U.S. Department of Energy, Washington, DC 20545

112. R. A. E. Bolton, IREQ Hydro-Quebec Research Institute, 1800 Montée-Ste.-Julie, Varennes, P.Q. JOL 2PO, Canada

113. D. H. Crandall, Experimental Plasma Physics Research Branch, Division of Applied Plasma Physics, Office of Energy Research, ER-542, Germantown, U.S. Department of Energy, Washington, DC 20545

114. R. L. Freeman, General Atomics, P. 0. Box 85608, San Diego, CA 92138-5608

115. K. W. Gentle, RLM 11.222, Institute for Fusion Studies, University of Texas, Austin, TX 78712

116. R. J. Goldston, Plasma Physics Laboratory, Princeton University, P.O. Box 451 , Princeton, NJ 08543

117. J. C. Hosea, Plasma Physics Laboratory, Princeton University, P.O. Box 451, Princeton, NJ 08543

118. D. Priester, Division of Confinement Systems, Office of Energy Research, ER-55, Germantown, U.S. Department of Energy, Washington, DC 20545

119. R. H. McKnight, Experimental Plasma Physics Research Branch, Division of Applied Plasma Physics, Office of Energy Research, ER-542, Germantown, U.S. Department of Energy, Washington, DC 20545

120. E. Oktay, Division of Confinement Systems, Office of Energy Research, ER-55, Germantown, U.S. Department of Energy, Washington, DC 20545

121. W. L. Sadowski, Fusion Theory and Computer Services Branch, Division of Applied Plasma Physics, Office of Energy Research, ER-541, Germantown, U.S. Department of Energy, Washington, DC 20545

122. J. W. Willis, Division of Confinement Systems, Office of Energy Research, ER-55, Germantown, U.S. Department of Energy, Washington, DC 20545

123. C. Alejaldre, Division de Fusion, CEMAT, Avenida Complutense 22, E-28040 Madrid, Spain

124. Laboratory for Plasma and Fusion Studies, Department of Nuclear Engineering, Seoul National University, Shinrim-dong, Gwanak-ku, Seoul 151, Korea 
125. Laboratorio Associado de Plasma, Instituto Nacional de Pesquisas Espaciais, Caixa Postal 515, 122201, Sao Jose dos Campos, SP, Brazil

126. J. L. Johnson, Plasma Physics Laboratory, Princeton University, P.O. Box 451, Princeton, NJ 08543

127. L. M. Kovrizhnykh, Institute of General Physics, Academy of Sciences, Ulitsa Vavilova 38, 117924 Moscow, Russia

128. 0. Motojima, National Institute for Fusion Science, Chikusa-ku, Nagoya 464-01, Japan

129. S. Okamura, National Institute for Fusion Science, Chikusa-ku, Nagoya 464-01, Japan

130. V. D. Shafranov, I. V. Kurchatov Institute of Atomic Energy, P.O. Box 3402, 123182 Moscow, Russia

131. J. L. Shohet, Torsatron/Stellarator Laboratory, University of Wisconsin, Madison, WI 53706

132. H. Wobig, Max-Planck Institut fur Plasmaphysik, Boltzmannstrasse 2, D-8046 Garching, Federal Republic of Germany

133. F. Najmabadi, 44-139 Engineering IV, Institute of Plasma and Fusion Research, University of California, Los Angeles, CA 90024-1597

134. R. A. Krakowski, MS F607, Los Alamos National Laboratory, Los Alamos, NM 87545

135. R. L. Miller, MS F607, Los Alamos National Laboratory, Los Alamos, NM 87545

136. H. E. Clark, U.S. Department of Energy, Oak Ridge Operations, Oak Ridge, TN 37831-6269

137. W. F. Dove, Division of Applied Plasma Physics, Office of Fusion Energy, Office of Energy Research, ER-543 Germantown, U.S. Department of Energy, Washington, DC 20545

138. S. Berk, Office of Fusion Energy, Office of Energy Research, ER-533 Germantown, U.S. Department of Energy, Washington, DC 20545

139. F. Perkins, Plasma Physics Laboratory, Princeton University, P.O. Box 451, Princeton, NJ 08543

140. N. H. Lazar, TRW Defense and Space Systems, Room 1280, Bldg. 01, One Space Park, Redondo Beach, CA 90278

141. T. Obiki, Plasma Physics Laboratory, Kyoto University, Gokasho, Uji, Kyoto 611, Japan

142. A. Iiyoshi, National Institute for Fusion Science, Chikusa-ku, Nagoya 464-01, Japan

143. G. Grieger, Max-Planck Institut fur Plasmaphysik, Boltzmannstrasse 2, D-8046 Garching, Federal Republic of Germany

144. K. Matsuoka, National Institute for Fusion Science, Chikusa-ku, Nagoya 464-01, Japan

145. R. E. Siemon, MS H854, Los Alamos National Laboratory, Los Alamos, NM 87545

146. R. F. Gandy, Physics Department, Auburn University, Auburn, AL 36849-3511

147. D. T. Anderson, University of Wisconsin, Madison, WI 53706

148. M. Wakatani, Plasma Physics Laboratory, Kyoto University, Gokasho, Uji, Kyoto 611, Japan

149. F. Wagner, Max-Planck Institut fur PLasmaphysik, Boltzmannstrasse 2, D-8046 Garching, Federal Republic of Germany 
150. L. El-Guebaly, University of Wisconsin, Madison WI 53706

151. I. Sviatoslavsky, University of Wisconsin, Madison WI 53706

152-190. Given distribution as shown in DOE/OSTI-4500, Magnetic Fusion Energy

(Category Distribution UC-420, Magnetic Fusion Energy) 

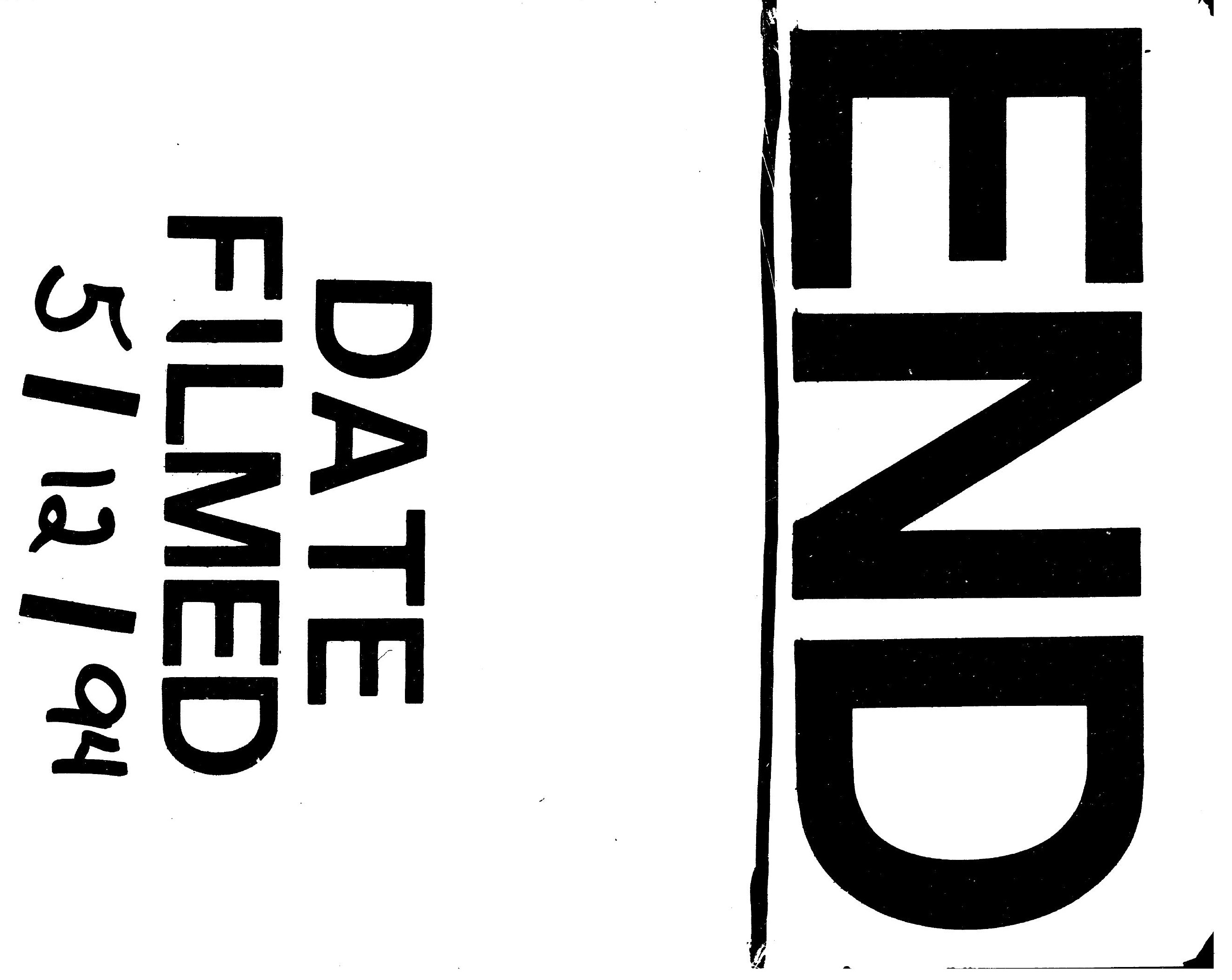